\title{
A review of aerosol jet printing-a non-traditional hybrid process for micro-manufacturing
}

\author{
N. J. Wilkinson ${ }^{1}$ - M. A. A. Smith ${ }^{1}$ R. W. Kay ${ }^{1}$ - R. A. Harris ${ }^{1}$
}

Received: 5 May 2018 / Accepted: 11 February 2019 / Published online: 9 May 2019

(C) The Author(s) 2019

\begin{abstract}
Aerosol Jet Printing (AJP) is an emerging contactless direct write approach aimed at the production of fine features on a wide range of substrates. Originally developed for the manufacture of electronic circuitry, the technology has been explored for a range of applications, including, active and passive electronic components, actuators, sensors, as well as a variety of selective chemical and biological responses. Freeform deposition, coupled with a relatively large stand-off distance, is enabling researchers to produce devices with increased geometric complexity compared to conventional manufacturing or more commonly used direct write approaches. Wide material compatibility, high resolution and independence of orientation have provided novelty in a number of applications when AJP is conducted as a digitally driven approach for integrated manufacture. This overview of the technology will summarise the underlying principles of AJP, review applications of the technology and discuss the hurdles to more widespread industry adoption. Finally, this paper will hypothesise where gains may be realised through this assistive manufacturing process.
\end{abstract}

Keywords Aerosol jet · Hybrid manufacture $\cdot$ Micro-manufacturing $\cdot$ Printed electronics $\cdot$ Direct write

\section{Introduction}

Direct write covers a range of processes that can selectively deposit material to produce freeform patterns. These processes are often investigated for the production of conductive traces [1-3]; however, the capabilities of direct write are being increasingly explored for the deposition of other functional [4-6] and structural inks [7-9]. Digitally driven and independent of orientation, direct write techniques are attractive for applications desiring conformity and design flexibility [10]. The high-value sectors of aerospace and healthcare provide significant motivation; however, as technologies mature, they are likely to be adopted more widely as engineers seek new functionality alongside improved performance and packaging. The diversity of applications provides a significant incentive

Wilkinson and Smith have made an equal contribution in the creation of this review.

N. J. Wilkinson

mnnjw@leeds.ac.uk

1 Future Manufacturing Processes Research Group, University of Leeds, Leeds, UK for the development of capable direct-write processes. This opportunity was recognised in the DARPA-funded MICE (Mesoscale Integrated Conformal Electronics) project in the late 1990s, which aimed to develop manufacturing processes capable of depositing a range of materials on to virtually any substrate [11]. The outcome was the development of a number of deposition mechanisms, most notably the Aerosol Jet and Nanojet systems that have since been commercialised by Optomec Inc. and Integrated Deposition Systems (IDS), respectively. The first research publications featuring Aerosol Jet Printing (AJP) began to emerge around 2001-2002 [12].

AJP (Fig. 1) introduced new capabilities to direct write through its use of a directed aerosol stream to provide consistent deposition at nozzle-substrate offsets of 1-5 mm [13]. This approach enables the patterning of more complex surfaces, which was well illustrated through the deposition of a spiral pattern on the surface of a golf ball [14]. For an assistive manufacturing technology - one that is intended to be used as part of a greater, hybrid manufacturing process - this flexibility simplifies control, accommodates less precise articulation and enables patterning on surfaces that cannot be reached by physical nozzles. This combination greatly simplifies process integration when compared with other direct write technologies. 


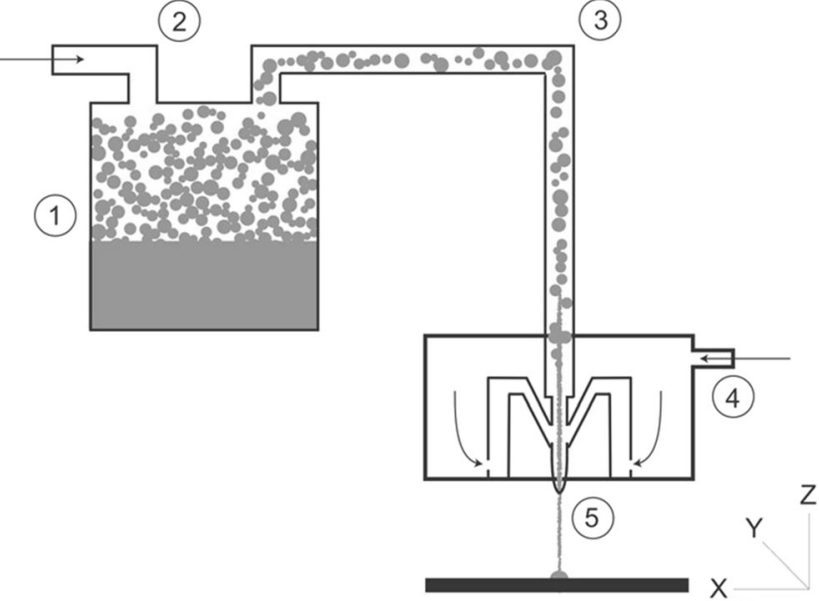

(6)

Fig. 1 An overview of AJP: (1) aerosol generation using either ultrasonic or pneumatic atomiser, (2) introduction of a carrier gas to transport the aerosol, (3) transportation and refinement, (4) focussing and (5) deposition and (6) computer-controlled translation of the substrate

In theory, any material that can be suspended within an aerosol is compatible with the AJP technique. Commercial systems use ultrasonic or pneumatic atomisation to generate an aerosol from inks with viscosities that range from 1 to $1000 \mathrm{cp}$. Tolerance of a wide range of materials presents opportunities beyond competing inkjet technologies, which are often limited to viscosities below $20 \mathrm{cp}$. Examples of materials deposited using AJP range from silver inks [15] and ceramics [16] to biological matter, such as proteins and strands of DNA [17]. Material flexibility does not come at the expense of resolution, with research groups claiming depositions in the region of $10 \mu \mathrm{m}[17,18]$.

The above-mentioned novelties provide promise for the field of AJP and the wider direct write approach. This review provides an overview of the process before discussing the current-state-of-the-art from an applications perspective. The future of AJP is, then, explored to provide an insight in to how it can mature for more widespread industry adoption. This review has avoided a comprehensive comparison with similar direct write technologies, such as inkjet printing, as this is can be found in existing literature $[3,19]$.

\section{Atomisation techniques}

Production of an aerosol with characteristics suitable for jetting requires an understanding of both the atomisation techniques and the rheological properties of the ink. The interplay between the surface tension, viscosity, volatility, and density of the material with the method of aerosolization presents unique challenges in process development. These issues are compounded by a high degree of process variability between inks of different types.
An ideal aerosol would be monodispersed, highly dense and contain droplets with sufficient inertia to be impacted on the substrate. Droplets must not be so large that they negatively affect the minimum feature size or cause nozzle clogging. Aerosolization is achieved through the application of either ultrasonic or pneumatic atomisation. The ultrasonic atomiser produces highly uniform aerosols; however, it is limited to inks with viscosities in the range of $1-10 \mathrm{cp}$. The pneumatic approach enables the atomisation of materials with a viscosity up to $1000 \mathrm{cp} \mathrm{[20],} \mathrm{but} \mathrm{it} \mathrm{sacrifices} \mathrm{the} \mathrm{uniformity,} \mathrm{or} \mathrm{mono-}$ dispersity, of the aerosol that is produced and requires extra flow refinement steps before deposition.

\subsection{Ultrasonic atomisation}

Ultrasonic atomisation produces an aerosol from small volumes $(\sim 2 \mathrm{ml})$ of low-viscosity $(1-10 \mathrm{cp})$ inks. Its operation principle is illustrated in Fig. 2; a transducer is submerged within a transfer medium, typically water, where it oscillates at high frequency (Fig. 2-1). A wave is propagated through the transfer medium to a vial suspended above the transducer (Fig. 2-2). Within the vial, a standing wave is formed on the surface and the superposition of consecutive waves results in the formation of large peaks (Fig. 2-3). Local shear at the top of these peaks results in small droplets being ejected from the bulk ink. Finally, a positive pressure is applied to the vial to drive the aerosol from the vial towards the deposition head (Fig. 2-4).

Aerosols produced using this technique are typically of low dispersity, with droplet sizes ranging from 2 to $5 \mu \mathrm{m}$ [19]. In practice, a user is likely to tailor the atomisation parameters and ink formulation to modify the droplet size and distribution in an attempt to minimise small satellite deposits at the edges of a deposition known as overspray (Section 3.1). The

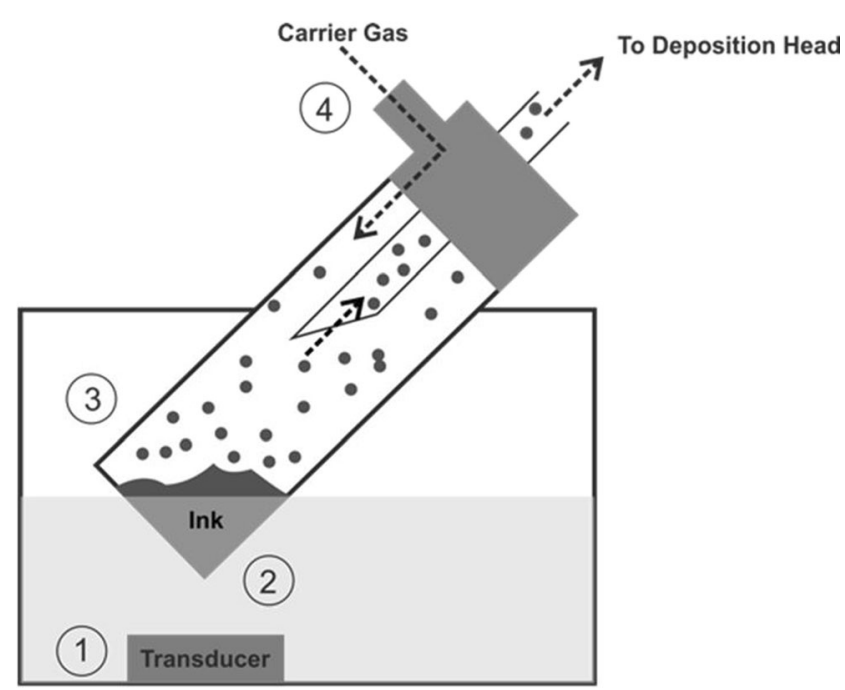

Fig. 2 Schematic of ultrasonic atomisation 
relatively low dispersity of the aerosol negates the need for secondary refinement stages.

\subsection{Pneumatic atomisation}

The pneumatic approach is tolerant of a greater range of viscosities - usually reported to be 1-1000 cp; however, Optomec's more recent datasheets suggest a conservative 1$500 \mathrm{cp}$. Atomisation is achieved using a variant of the welldocumented Collison-style atomiser that has previously been used for the aerosolization of bacterial suspensions. Designs, descriptions and applications of this type of atomiser can be found in the literature; with May's 1972 report providing a detailed design study [21].

Figure 3 shows a schematic of a typical Collison atomiser. During atomisation, a carrier gas is accelerated across the top of an ink supply channel (Fig. 3-1). This creates a region of reduced static pressure that draws the ink to the carrier gas flow. When the ink reaches the level of the carrier gas stream, the topmost layer is sheared producing a series of polydisperse droplets (Fig. 3-2). Large, high-inertia droplets within this stream are impacted on the side wall of the atomising chamber and return to the reservoir (Fig. 3-3), while lower inertia droplets remain as an aerosol and are exhausted from the atomiser towards the virtual impactor (Fig. 3-4).

Following atomisation, the aerosol is transported to the virtual impactor (Fig. 4-1), which uses a region of stagnant flow to separate droplets within an aerosol stream based on their inertia (Fig. 4 -2). Small droplets, which have insufficient inertia to overcome this region, are ejected radially in to the major flow (Fig. 4-3). As low inertia droplets contribute

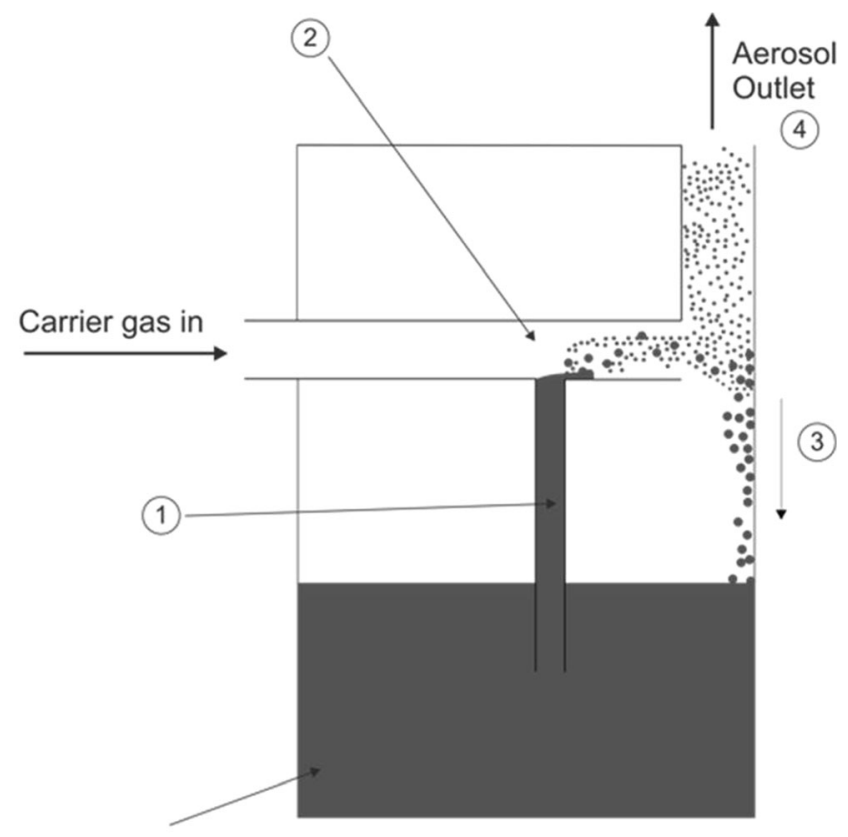

Material Reservoir

Fig. 3 A schematic of pneumatic atomisation

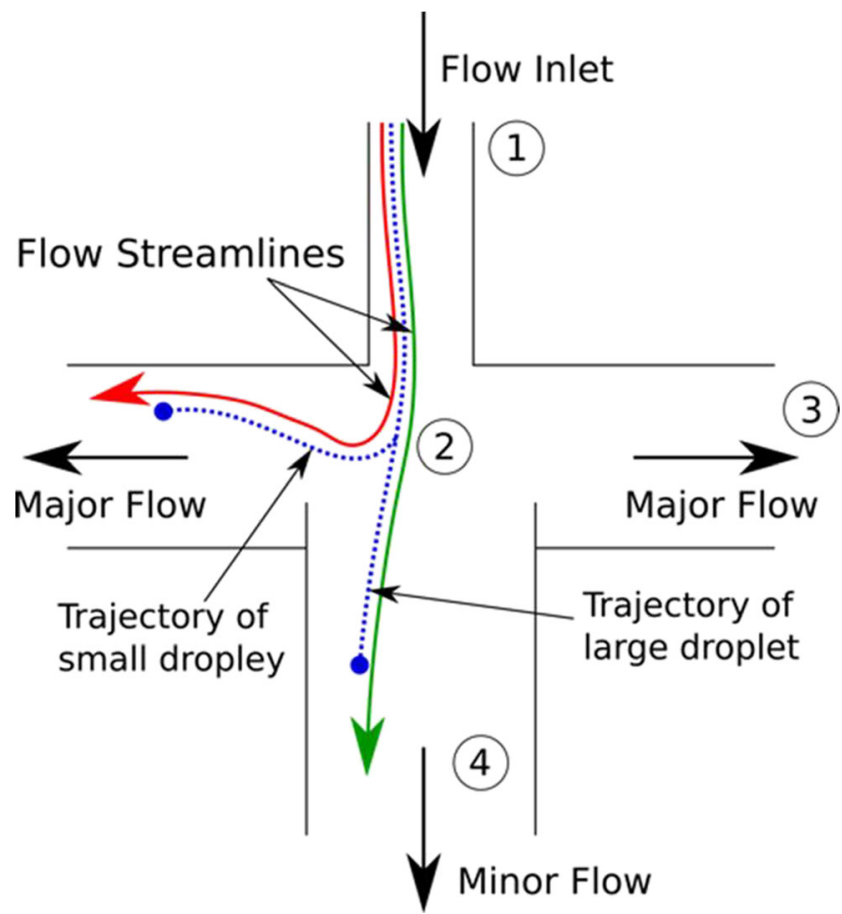

Fig. 4 Schematic of a virtual impactor

to overspray in AJ, these are usually collected or vented to the atmosphere. Large, high-inertia droplets are able to pass through the stagnant flow region and continue towards the deposition head (Fig. 4 - 4).

\section{Focussing and deposition}

Once a suitable aerosol has been produced, it is transferred to the deposition head by a carrier gas flow (Fig. 5-1) where it is focussed using a virtual and physical nozzle. The introduction of a secondary flow (Fig. 5-2) constrains and constricts the aerosol within an annular sheath that forms an interlayer between the aerosol and the physical components (Fig. 5-3). The aerosol and its annular sheath are further focussed through a physical nozzle before being deposited on to the substrate (Fig. 5-4).

The application of a sheath gas results in characteristics that are unique to AJP; the aerosol flow is collimated, which enables consistent deposition at a $1-5 \mathrm{~mm}$ stand-off; the interlayer between the aerosol stream and the material reduces the instances of nozzle clogging; and, through the manipulation of the aerosol flow rate relative to the sheath, it enables inprocess control of the deposition geometry without changes in hardware. The combination of virtual and physical nozzles allows deposits that are one tenth the size of the nozzle's orifice [9]. A challenge for focussing using a sheath comes from its interaction with the substrate and previous deposits, especially if they are in liquid or powdered forms. 
Fig. 5 Schematic of a deposition head [1]

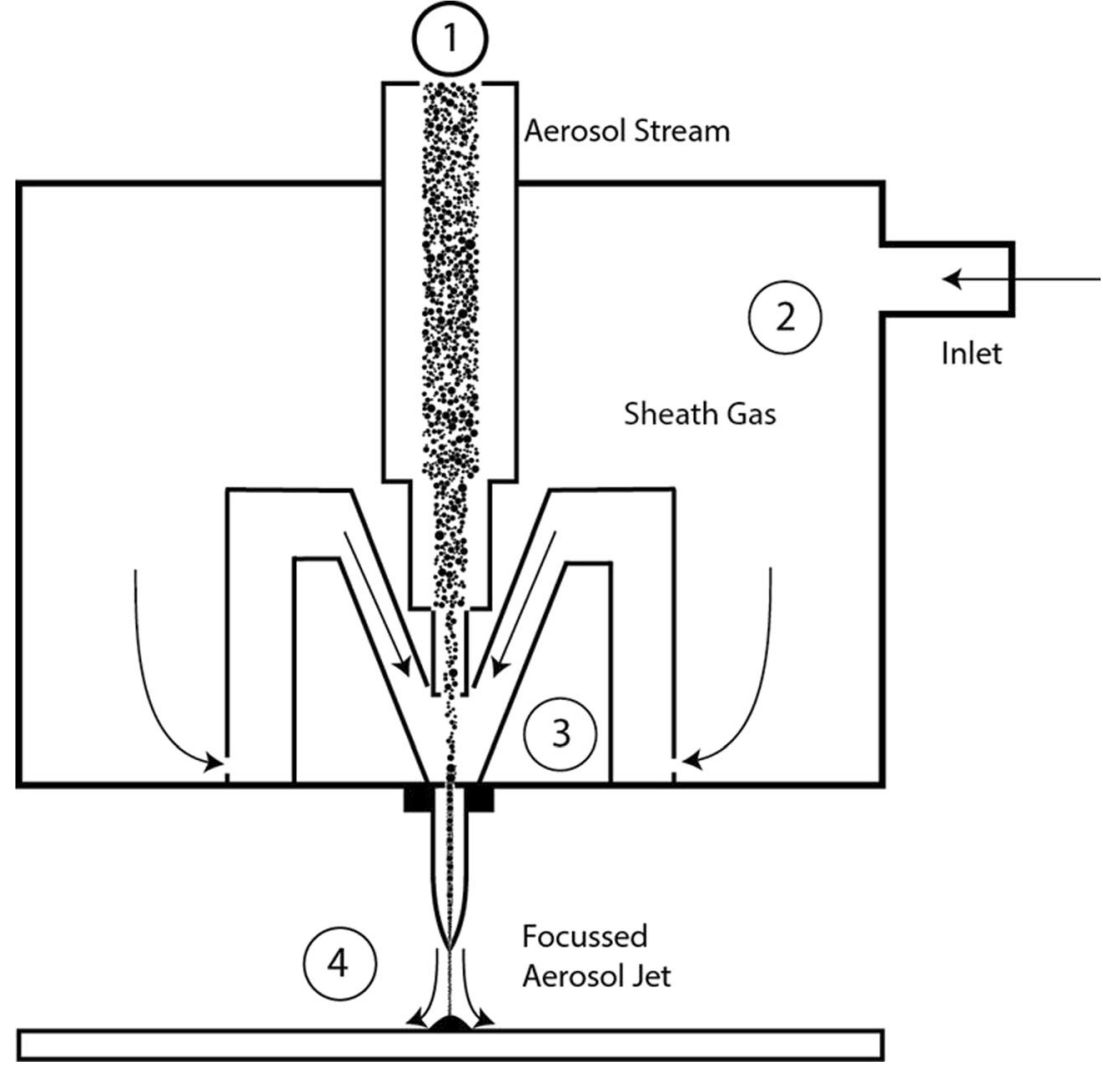

\subsection{Factors affecting deposition}

Deposit quality is reliant on a multitude of factors (Fig. 6); the apparatus, process and design are readily configurable, while the substrate and environmental factors are more difficult to control, especially in the context of industrial production lines. Material and ink formulation present arguably the biggest challenge, and their development is discussed at more length in Section 4. Research groups have begun investigating the effect of process parameters $[1,22,23]$, and the fundamental principles of AJP have, recently, been well presented [24].
Goth et al. [22] conducted a study with a focus on the adhesiveness, conductivity and wetting characteristics for silver and palladium inks at varying processing parameters and substrate surface energies. They report that plasma treatment of the substrate's surface prior to AJP increases material spreading and adhesion. Mahajan et al. [1] built on this work and were the first to identify the focussing ratio- the ratio of the sheath gas flow rate to the carrier gas flow rate - as a key parameter for the printing of fine features using AJP. The importance of the focussing ratio was reaffirmed during an analytical study on AJP by Binder et al. [25]. More recently, Smith et al.
Fig. 6 Parameters effecting aerosol jet printing (adapted from [22])

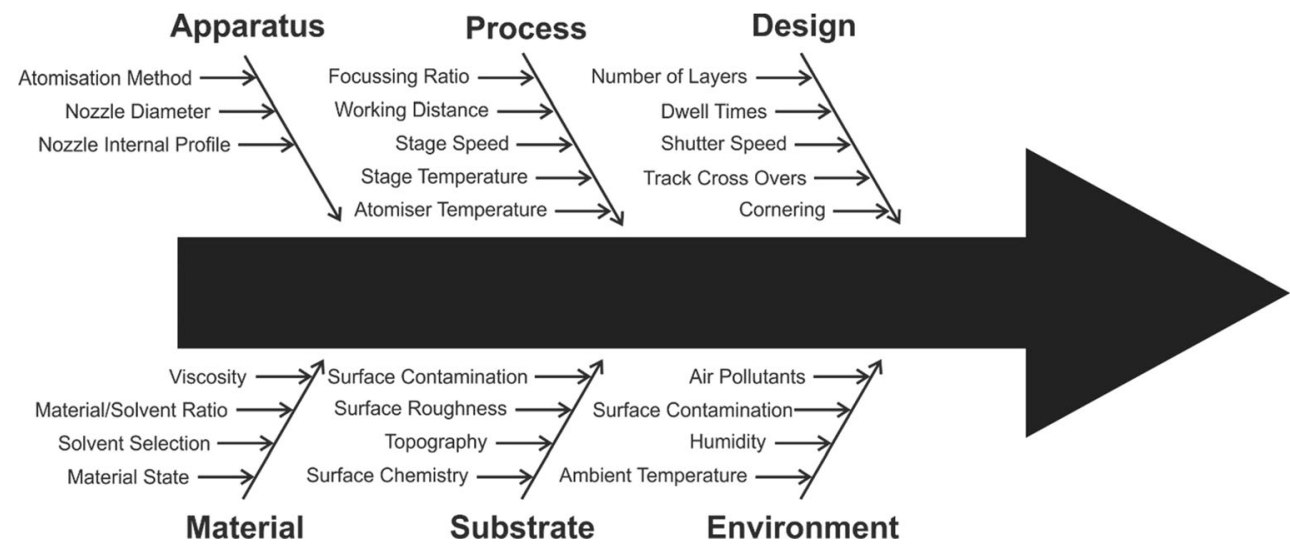


[23] conducted an investigation of processing parameters and expanded the study to include the substrate temperature.

In all of these studies, minimising overspray is identified as a challenge for AJP during initial process development. The overspray deposits (Fig. 7) are the result of droplets with insufficient inertia to be impacted close to the centre line of the aerosol flow before spreading with the carrier and sheath gas [24]. Assuming the droplets all have the same density and velocity, these inertial differences will result from variation in the volume of the droplets, which can be controlled to a degree though the ink composition, atomisation parameters and virtual impaction. For any reasonably developed process, overspray is merely an artefact of deposition mechanism and its consequence is primarily as a metric for defining line quality.

Improving edge definition and overall line quality by minimising overspray is currently achieved through empirical optimisation. Analytical models aiming to increase understanding of the deposition mechanism are starting to be developed, which will lead to a greater appreciation of the interdependence of process parameters and accelerate the development of robust print recipes $[24,26]$.

Objective metrics that can distinguish between poorand high-quality lines will be important for AJP as it transitions away from a reliance on user intuition. For conductive traces, Smith et al. [23] developed a method for quantitatively defining line quality by comparing the full-width at half-maximum height (FWHM) to a measurement of the distance between the edges of the overspray. If this measurement, known as the effective width, was found to be significantly greater than the FWHM, then the line was deemed to be of poor quality as much of the deposit did not contribute to its current carrying capacity. Salary et al. [27] have started to develop an in-process monitoring tool that extracts six metrics (line width, line density, edge smoothness, overspray index, line discontinuity and Fiedler number) from optical micrographs to determine the quality of deposit. They hope to eventually implement a system for closed-loop control of the AJP process.

Often overlooked, transportation losses can also have a large impact on the quality of the final deposit. Secor [24] published a model for the transportation losses and highlighted gravitational settling as the predominant factor with diffusion, machine geometry and ink formulation also playing important roles. Losses during transportation can account for non-linearities in the deposition rate with increasing aerosol flow, if it is assumed that the density of the aerosol is constant. In practice, longer transportation tubing requires greater aerosol flow rates for equivalent losses, meaning machine configurations that generate an aerosol at a distance from the deposition head will experience greater losses than those that generate the aerosol locally. More recent iterations of the Optomec and Nanojet systems have integrated the atomisation assembly on to the deposition head, which is perhaps indicative of this effect.

Secor [24] argues that through considered design of these flow pathways, the losses could be harnessed to narrow the distribution of droplets within an aerosol flow. Although attractive in principle, the limited gains achievable through this approach are unlikely to be worth the empirical efforts compared to other techniques, such as virtual impaction or optimisation of the ink and processing parameters.

\section{Material development}

The formulation of a suitable ink is key for depositions with desirable morphologies and functional characteristics and, as a result, is one of the most active areas of research for AJP. Although accommodating of a wide variety of ink solutions, suspensions and viscosities (Table 1), initial formulation and optimisation are achieved through large, isolated bodies of empirical work due to a lack of fundamental understanding and process models. A description of the conditions required to develop a jettable ink, comparable to the "Z number" used for inkjet printing, would likely accelerate development times and research outputs [28].

Part of this challenge is understanding and effectively controlling evaporation during atomisation, transportation and deposition. Low-boiling point solvents evaporate in flight and, when used alone, can result in the deposition of discrete, dry particles that produce features with high surface roughness
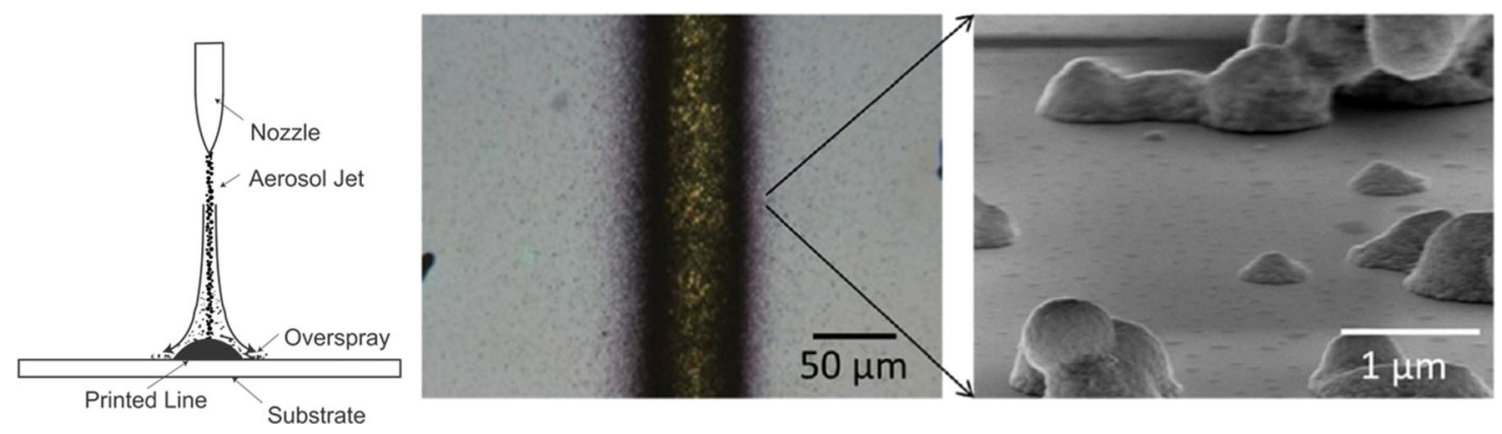

Fig. 7 Overspray in AJP deposits [1] (Reprinted with permission from [1]) 
Table 1 Material recommendations

\begin{tabular}{lll}
\hline & Ultrasonic atomisation & Pneumatic atomisation \\
\hline Suitable phase & Solvents, solutions, dispersions & $\begin{array}{c}\text { Solutions, dispersions, } \\
\text { liquid monomers, melts }\end{array}$ \\
Maximum viscosity & $5 \mathrm{cP}$ & $1000 \mathrm{cP}$ \\
Maximum solid loading (dispersions) & $55 \mathrm{wt} . \%$ & $75 \mathrm{wt} \%$ \\
Maximum particle size (dispersions) & $50 \mathrm{~nm}$ & $500 \mathrm{~nm}$ \\
Predominant solvent type & Low boiling point & High boiling point \\
\hline
\end{tabular}

and porosity. A loss of mass through evaporation can lead to droplets with insufficient inertia for impaction, which can prevent patterning and emit more particles in to the atmosphere than on to the substrate [24]. Yang et al. [29] stipulated that the production of flat features requires the deposition of a thin liquid layer that can be dried in situ through the effects of the sheath gas and a heated substrate. This behaviour is commonly achieved through a combination of high and low volatility solvents. The high volatility solvent is evaporated shortly after atomisation, which saturates the carrier gas and leads to a stable droplet volume during transportation until the aerosol stream interacts with the sheath gas. At this point, the low volatility solvent will begin to evaporate. Total drying of the particles before deposition can usually be avoided by including $\sim 10 \%$ of low volatility co-solvent within the ink [24].

These hurdles, combined with the adhesion, wetting and drying challenges facing nearly all direct write process, are being readily addressed for AJP in both research and commercial settings. Continued development is likely to lead to a better understanding of the process that will decrease development timescales, drive down cost and ultimately lead to more widespread industrial adoption.

\section{Applications}

An array of applications have been identified for AJP that hope to deploy its material and spatial freedom to create new types of products with increased functionality. Most work, to date, has been centred on the production of printed electronic devices using unconventional materials and substrates. However, the technology is starting to be explored to expand capabilities in diverse research topics. For the purposes of this review, the different bodies of work have been grouped based on their primary application area (Fig. 8).

\subsection{Passive electronic components}

Passive electronic components are those that do not increase the net power of the circuit and whose output is not controlled by another signal (e.g. resistors [30], capacitors [16, 31] and inductors [32]). Their relative simplicity makes them an achievable application for most implementations of AJP, provided the material can be printed reliably. Printing passive electronic components reduces their space claim and allows greater integration of electronic circuitry with fewer processing steps, while the ability to print onto non-planar surfaces surpasses other technology in this area.

\subsubsection{Interconnects}

AJP is widely demonstrated as a technique for printing conductive traces designed to connect two or more electronic components. This approach is a promising free-form, threedimensional and mask-less substitute for template-driven technologies, such as photolithography, chemical etching and screen printing. AJP has an opportunity to enable a new era of electronics on unconventional substrates. The simplicity of electrical interconnects has made them the primary structure for the evaluation of conductive materials.

Early work on interconnects used a silver nanoparticle ink as a seed layer for a secondary light-induced plating process on glass and silicone substrates for the front side metallisation of solar cells $[33,34]$. The AJP nanoparticle ink was used to produce a high-quality electrical and mechanical contact with the silicon solar cell, while the light-induced plating process provided a higher conductivity finger for more efficient transfer of charge. Fraunhofer ISE have continued to develop the seed-plating process through investigation of scale-up [34] and material development $[35,36]$. Functional circuitry using only AJP followed shortly after when Padovani at al. [37] deposited silver nanoparticle inks on glass as $35 \mu \mathrm{m}$ interconnects between LEDs in a transparent head-up display (Fig. 9).

The flexibility in stand-off heights enables the production of vertical interconnects for multi-layer circuitry and stacked componentry. Vertical interconnects, or vias, were developed by Zhan et al. [38]. By shaping holes between circuit layers in to trapezoidal and reverse-trapezoidal geometries, they were able to create effective connections by jetting a silver ink in to the recesses. Once sintered, the vias were functional provided that the cooling rate was controlled to prevent cracking through the thermal shock. Out-of-plane interconnection of stacked components on a PCB substrate using 25- $\mu \mathrm{m}$ AJP silver lines has been shown to be an effective way to produce compact packaging (Fig. 10) [39]. The conductivity of the silver tracks produced during this work was found to be $8 \%$ 
Fig. 8 Applications of AJP

\begin{tabular}{|c|c|c|c|}
\hline \multirow{4}{*}{ (7) } & \multirow{13}{*}{ 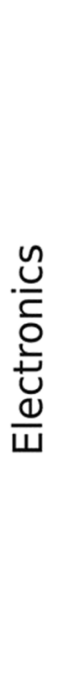 } & \multirow{4}{*}{ Passives } & Interconnects \\
\hline & & & Capacitors \\
\hline & & & Inductors \\
\hline & & & $\begin{array}{l}\text { Antenna, waveguides } \\
\text { and transmission lines }\end{array}$ \\
\hline & & \multirow{4}{*}{ Actives } & Transistors \\
\hline \multirow{3}{*}{$\subsetneq$} & & & OLED \\
\hline & & & Photovoltaics \\
\hline & & & Fuel Cells \\
\hline J & & \multirow{5}{*}{ Sensors } & Strain Gauges \\
\hline & & & Capacitive Sensors \\
\hline & & & Dielectric Elastomer Devices \\
\hline & & & Photodetectors \\
\hline & & & Chemical Sensing \\
\hline & \multicolumn{3}{|c|}{ Three-Dimensional Structures } \\
\hline & \multicolumn{3}{|c|}{ Applications in Biology } \\
\hline
\end{tabular}

of bulk silver. Syed-Khaja et al. [40] have shown die attachment through the sintering of AJP silver pads.

An investigation in to the compatibility of AJP-deposited silver ink and conventional wire bonding has shown limited bond strength for $\mathrm{Au}$ and $\mathrm{Al}$ wire bonding. In their work, Stoukatch et al. [41] suggested that silver inks themselves may prove to be an alternative for substrates with low thermal capabilities. Ultrasonic wire bonding has been shown to be a more effective technique for joining AJP silver deposits to components on both glass and polythalamide substrates [42].
The attachment of micro-electromechanical systems (MEMS) to circuits has also been achieved through AJP [43].

One of the primary advantages of AJP is its ability to produce fine features [44]. Kopola et al. [45] demonstrated improved device performance by decreasing the width of tracks in the current collection grid of an inverted, ITO-free solar cell. In this preliminary work, comparatively large mean line widths of $58.1 \mu \mathrm{m}$ were achieved. Mahajan et al. [1] conducted a more comprehensive study on the optimisation of highresolution $(20 \mu \mathrm{m})$, high-aspect ratio $(0.1)$ silver lines, in
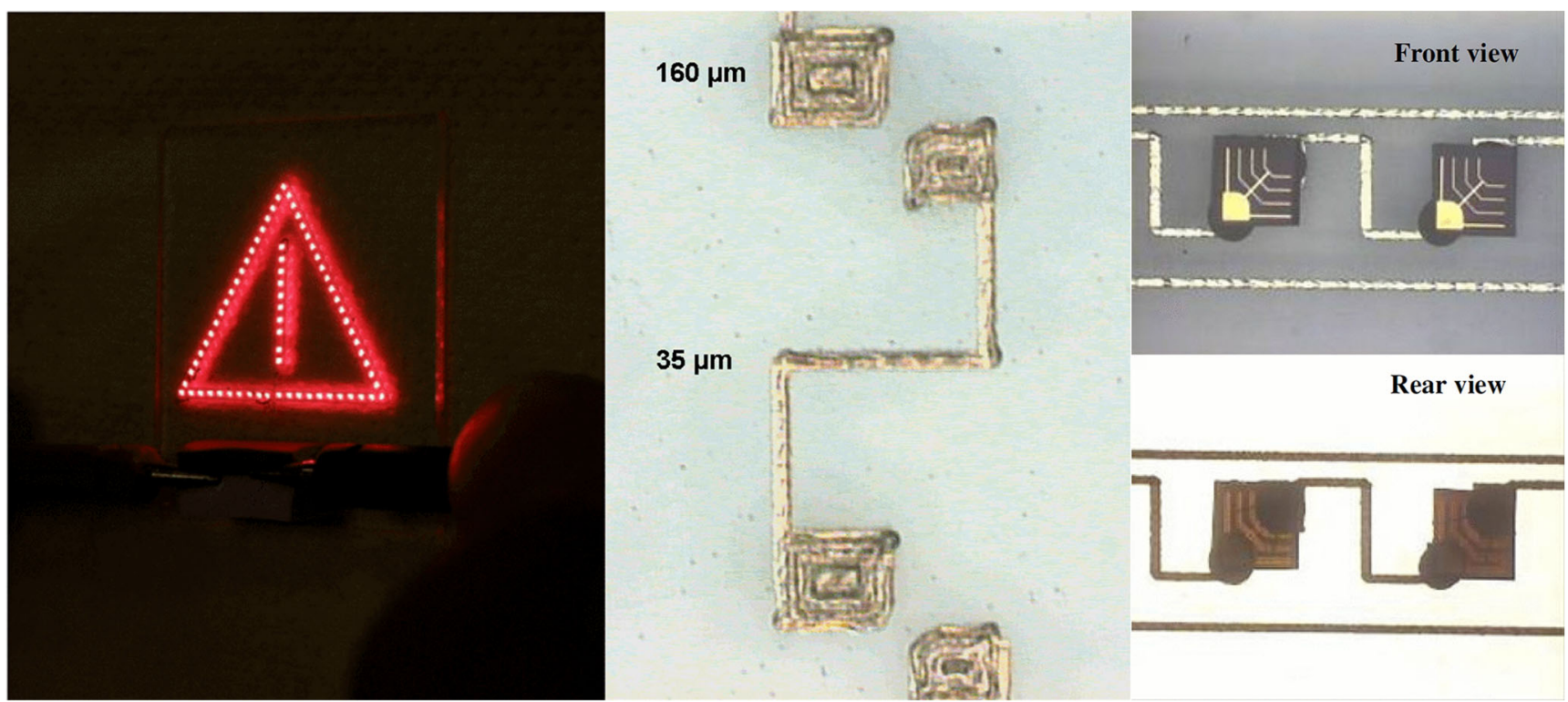

Fig. 9 AJP deposited silver interconnects in a head-up display (ㄷ 2010 IEEE. Reprinted, with permission, from [37]) 


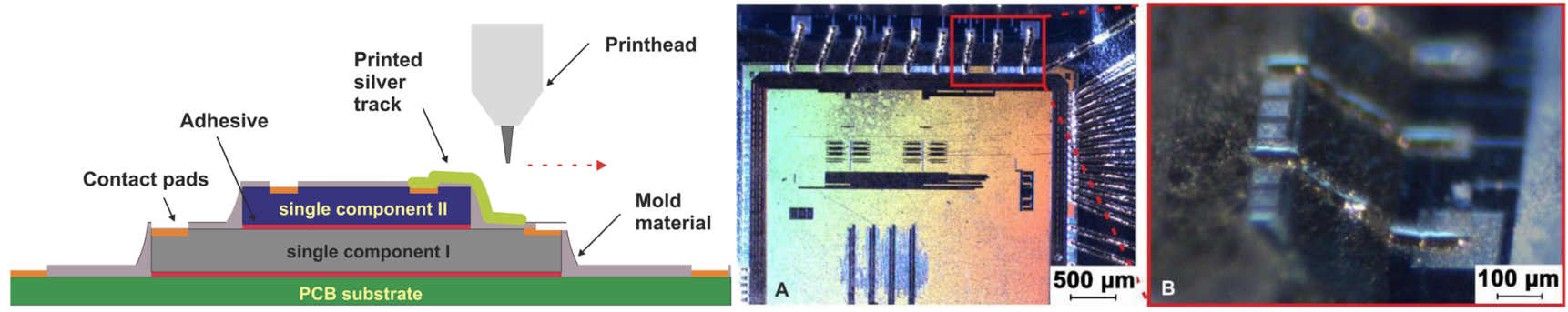

Fig. 10 Interconnection between stacked PCB components (Reprinted with permission from [39])

which the electrical properties of the deposit were correlated to the processing parameters. Resistances roughly double that of bulk silver were achieved; however any variation in processing parameters (low focussing ratio and high translational velocities) leads to increased porosity and, therefore, increased resistance [1]. To the best of the authors' knowledge, the finest reported conductive metallic lines produced using AJP were produced by Cai et al. [18] who presented line widths of $10 \mu \mathrm{m}$ using a silver ink (Fig. 11).

Although AJP has been shown useful in the production of fine pitch interconnects, Mashayekhi et al. [46] argue that it is limited when producing tracks with lengths less than $100 \mu \mathrm{m}$. During a comparison of printing techniques for electronic applications, their work shows that the characteristic bulges at the end of AJP tracks coalesce and form a droplet-like deposition, effectively limiting the print resolution [46].

Wetting characteristics of the substrate are well known to affect the morphology of any deposit. Vunnam et al. [47] investigated the effects of air plasma and self-assembled monolayer treatments on the adhesion of AJP-deposited silver ink on an indium tin oxide substrate. Ultimately, they found the ink spreading to be strongly dependent on the substrate's surface free energy, ink properties and sheath flow [47]. Mahajan et al. [48] have shown how AJ printing on to low energy substrates can facilitate a transfer process for producing low roughness $(<10 \mathrm{~nm}$ ) silver ink tracks (Fig. 12). Chang et al. [49] have used a similar print-transfer-peel technique to produce circuitry on to flexible substrates. As well as producing low surface roughness interconnects, this approach allowed the researchers to overcome capillary action- induced wicking in channels caused by stair-steps on the surface of additively manufactured components. This approach also facilitated patterning on low-temperature substrates as the ink could be sintered before transfer.

Thermal sintering is an important processing step in the development of highly conductive traces. Both Shankar et al. [50] and Werner et al. [51] have demonstrated, quantitatively, the impact of thermal sintering on the conductivity of silver deposits. Their results show that higher sintering temperatures can lead to increased conductivity through more complete evaporation of ligands and a greater degree of coalescence. At a similar time, however, Goth et al. [2] showed that thermal sintering can present issues with interconnect cracking due to differences in the coefficient of thermal expansion between the ink and the substrate. Seifert et al. [39] showed that multi-layered $(>10)$ printed silver tracks tend to peel during sintering as result of residual stresses. Rahman et al. [52] conducted a study investigating the hightemperature stability of AJP silver nanoparticle ink postsintering, finding that the post-sintering impedance of the deposit increases up to $150{ }^{\circ} \mathrm{C}$, decreases between 150 and $300{ }^{\circ} \mathrm{C}$ and, then, increases again as the temperature approaches $500{ }^{\circ} \mathrm{C}$. Decreases in conductivity were largely attributed to grain growth at elevated temperatures.

For materials that are not compatible with the temperatures associated with sintering (e.g. common thermoplastics), Hoerber et al. [53] showed that non-sintered deposits with larger interconnect dimensions can be used, while Werner et al. [51] presented electrical sintering as an alternative for thermally sensitive substrates. In later work, Schuetz et al. [54]
Fig. 11 AJP silver ink tracks at (a) $20 \mu \mathrm{m}$ grid (Reprinted with permission from [1] and (b) $10 \mu \mathrm{m}$ tracks (C) [2016] IEEE. Reprinted, with permission, from [18])

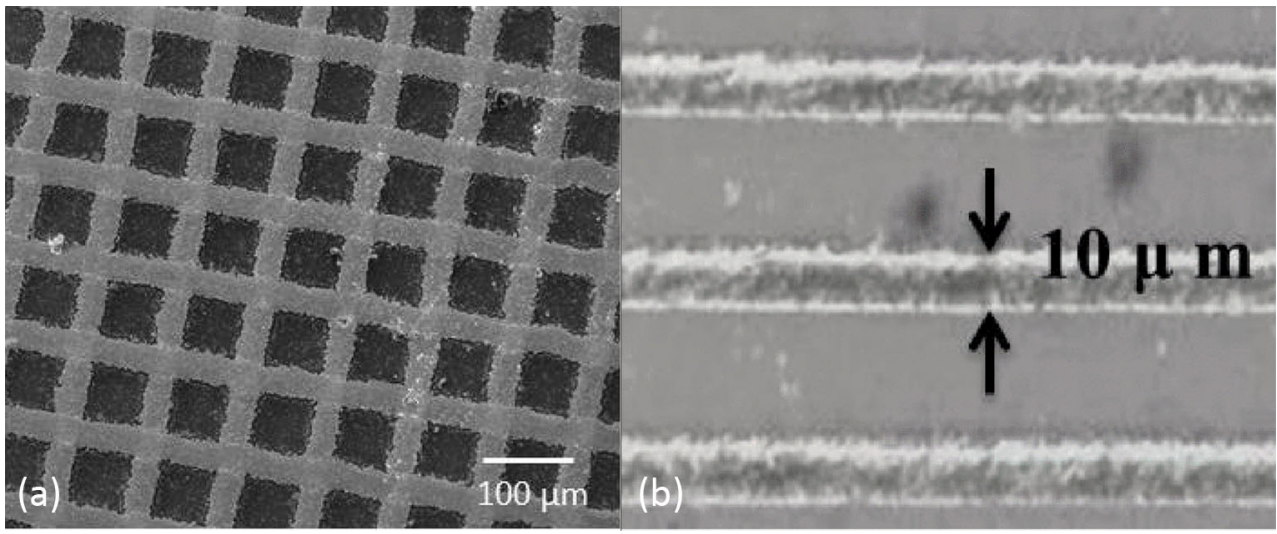


$A$

Apply coating of a reactive polymer on flexible substrate
$B$

Aerosol-jet print \& sinter silver lines on a low energy substrate

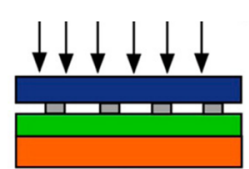

Invert and place $\boldsymbol{B}$ over wet polymer coating

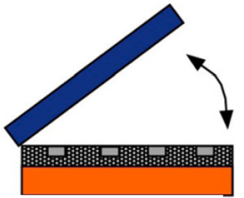

Delaminate $\boldsymbol{B}$

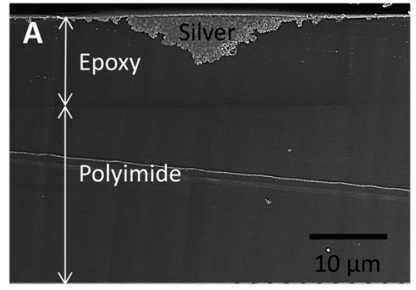

Fig. 12 Transfer process for highly flat conductive tracks adapted from (Reprinted with permission from [48])

developed a new technique for sintering metallic deposits using selective exposure to a xenon light source. Their approach allowed for the sintering of silver tracks on a polycarbonate substrate with limited substrate damage.

The use of nanoparticle inks presents serious limitations for the application of AJP interconnects. The high surface area-tovolume ratio of metallic nanoparticles makes them highly susceptible to loss of conductivity through oxidation. Silver ink is most commonly used as it is less prone to oxidation than copper-based inks. A comprehensive review of ink development is beyond the scope of this report. Reviews of conductive inks are readily available $[19,55]$.

AJ printing of metallic inks is a promising technique for the production of conformal, rigid circuitry. However, as determined by Reboun et al. [56], metallic-sintered conductive patterns have insufficient bending endurance $(<10,000$ cycles) for flexible applications (Fig. 13). Alternative conductive materials based on polymers, polymer matrices or forms of carbon are often presented as solutions.

Jabari and Toyserkani [57] investigated the deposition of graphene-based interconnects and achieved resistivity as low as $0.018 \Omega \mathrm{cm}$. Low concentrations of graphene inks are required to reduce instances of nozzle clogging, which limits the conductivity of the interconnects. A follow-up study attempted to overcome this through the combination of graphene and silver nanoparticle inks [58], which provided the flexibility of the graphene electrodes with a 100 factor increase in conductivity.

Wang et al. [59] demonstrated a "Conductive-On-Demand" approach to produce composite polyimide/carbon nanotube conductive devices that use inherent process characteristics to facilitate in-process mixing of multiple materials (Fig. 14). Two materials were atomised separately then combined in a static mixer before entering the deposition head. Through control of the relative flow rates, the conductivity of the composite could be spatially varied by adjusting the weighting of carbon nanotubes during the process (Fig. 14).

Beyond electrical circuitry, optical waveguides are a promising alternative for applications that need higher speed communication and data transfer than is achievable using conductive traces. Current manufacturing techniques are limited to planar designs connected by inefficient optical junctions [60]. Additive techniques that enable freeform optical waveguides are an attractive pathway for compact and efficient optical circuitry. The first demonstration of polymer optical waveguides (POW) using AJP was achieved by depositing a UV curable photopolymer on to a glass substrate [61]. Wetting of the photopolymer proved challenging and required a ten-minute exposure to ethylene glycol to adapt the surface energy of the substrate. Attenuation of the light source was found to be $2.8 \mathrm{~dB} / \mathrm{cm}$, which showed poor performance compared with other POW techniques $(<0.5 \mathrm{~dB} /$ $\mathrm{cm}$ ). Subsequent work improved the quality of the POW by using flexography to deposit conditioning lines that locally alter the contact angle of the substrate [62]. By increasing the aspect ratio of the AJP structures, POWs with a significantly improved attenuation of $0.7 \mathrm{~dB} / \mathrm{cm}$ were achieved. The repeatability of both the flexographic and AJP process has been identified as key challenges for printed POWs [63].

\subsubsection{Capacitors}

Ha et al. [64] sequentially deposited poly(3-hexylthiophene) (P3HT) and an electrolyte ion-gel on to pre-patterned gold electrodes to form the dielectric layer of a thin film capacitor. The top electrode was applied by printing PEDOT:PSS on to the surface of the ion gel. The time delay of the device was
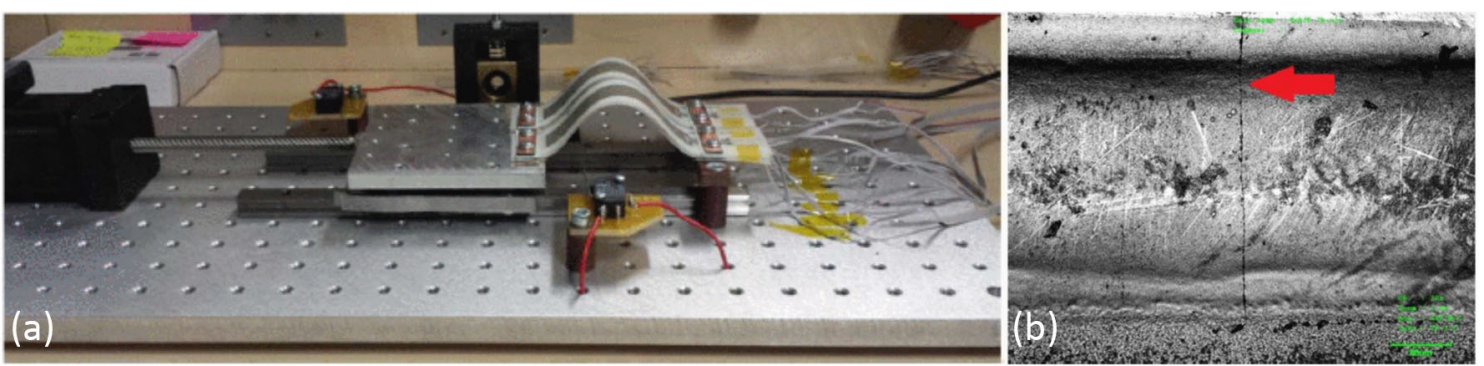

Fig. 13 (a) Apparatus for the testing of bending endurance of AJ-printed tracks and (b) cracks in AJ-printed tracks after 10,000 cycles (Reprinted with permission from [56]) 


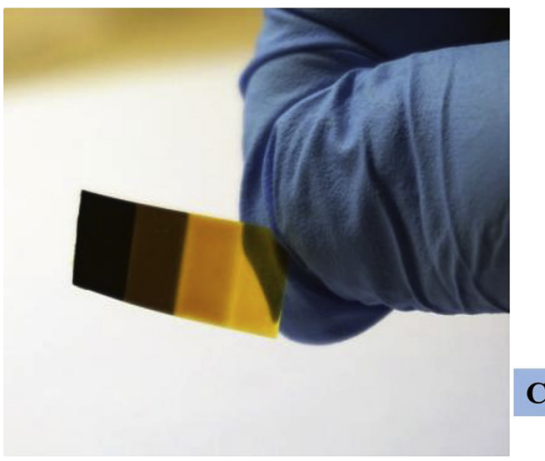

From built-inflow regulator

Nitrogen

From MKS flow regulator

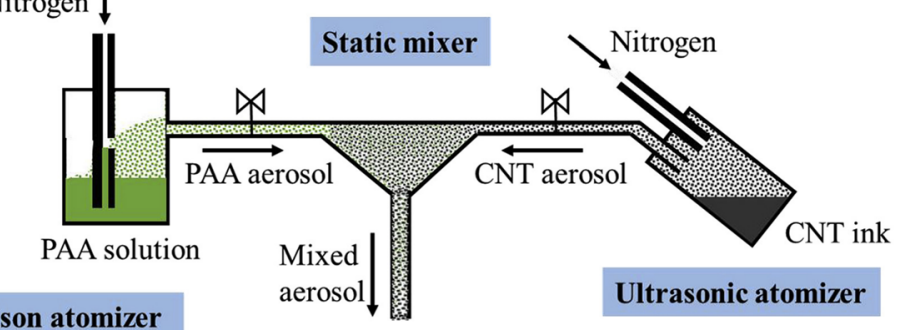

Collison atomizer

To deposition head

Fig. 14 "Conductive-on-demand" through the selective introduction of CNTs in to polyimide (Reprinted from [59])

found to linearly increase with the thickness of P3HT layer up to $400 \mathrm{~nm}$. A fully printed capacitor was produced by Gupta et al. [15] by printing silver traces alongside SU-8 photoresist as a dielectric medium. Increasing the area of overlap on the printed devices showed a linear increase in capacitance, which provides a simple pathway for tuning the capacitance to match the requirements of the circuit.

Folgar et al. [16] investigated the production of ceramic capacitors by depositing barium titanate particles before using selective laser sintering to form a continuous film. Development of an ink that was compatible with both processes proved challenging as ceramic binders inhibited the sintering process. Functional devices, with a capacitance of $17.5 \mathrm{pF}$ at $1 \mathrm{MHz}$, were produced by introducing silver electrodes either side of the ceramic along with a PMMA interlayer to minimise diffusion. The tested devices featured green state (non-sintered) ceramic as challenges with high porosity and delamination were difficult to overcome.

\subsubsection{Inductors}

AJP has been used to successfully print inductors by the deposition of a silver-based conductive ink, a magnetic nickel iron core and a muscovite mica dielectric [32]. The rudimentary nine-and-a-half turn inductor was produced in five processing steps, with conductive coils being the first and last printed layers to form a coil around the magnetic material. The coils were insulated from the magnetic core through the deposition of the dielectric on either side. The total thickness of the five layer device was less than $70 \mu \mathrm{m}$ with a length of $20 \mathrm{~mm}$ and width of $8 \mathrm{~mm}$. Besides ink development, the key step in this process was the removal of oxygen from the iron oxide and subsequent alloying with the nickel material post-deposition. Complete sintering is typically achieved at $80 \%$ of the melting point of the permalloy $\left(1440{ }^{\circ} \mathrm{C}\right)$; however, the sample produced using AJP was able to be sintered at $500{ }^{\circ} \mathrm{C}$ and $350{ }^{\circ} \mathrm{C}$ on glass and Kapton, respectively. The final device was found to have a fairly stable inductance $1.5 \mu \mathrm{H}$ at frequencies above $100 \mathrm{kHz}$. Devices with commercially relevant inductances have been produced using silver ink in combination with polymer, iron and ferrite cores [65]. Polymer core inductors were printed in situ, while the iron and ferrite cores were placed before an insulating polymer layer was deposited. A number of inductor geometries showed the flexibility of the manufacturing process for printed inductors.

\subsubsection{Antenna, waveguides and transmission lines}

Single-layer, planar antenna has been presented in several forms, with most research focussing on the deposition of a silver-based ink to produce the conductive traces on a dielectric substrate. When investigating the production of radiofrequency identification (RFID) tags, Cai et al. [66] printed a silver seed for electroless copper plating, which increased the conductivity of the deposit and improved the quality factor of the antenna. The electroless plating process was found to strip the silver seed from the substrate unless an adhesive interlayer was applied. Although the final adhesive strength was not quantified, RFID tags with inductances in the range of 2.87$2.97 \mathrm{uH}$ were successfully produced.

Three-dimensional antennas were produced through the deposition and UV curing of a dielectric ink to form pillars and hollow cylinders (Fig. 15). Conductive silver ink was, then, printed on the vertical walls of these structures using a tilted print head to produce functional, three-dimensional millimetrewave antenna. In the work, the authors argue that this approach to antenna design and manufacture opens up the possibility of an entirely new class of three-dimensional antenna $[68,69]$.

Deposition of dielectric materials alongside the conductive material has been presented as a technique for multi-layer coplanar waveguides capable of operation up to $50 \mathrm{GHz}$ with losses of $0.5 \mathrm{~dB} / \mathrm{mm}$ [70]. In this case, a polyimide ink was deposited as the dielectric alongside the silver to produce multilayer devices. Further work investigated single layer, radiofrequency waveguides on a diamond substrate [71]. Similar techniques have been used to produce other high-frequency electronic components, such as transmission lines [72] and power dividers [73]. Oakley et al. [74] did a direct benchmarking of AJP terahertz filters with equivalent copper filters produced using photolithographic techniques and found 
Fig. 15 (a) Vertical metal antenna on a dielectric pillar and (b) antenna microstructures (C) IOP Publishing. Reproduced with permission from [69]. All rights reserved)

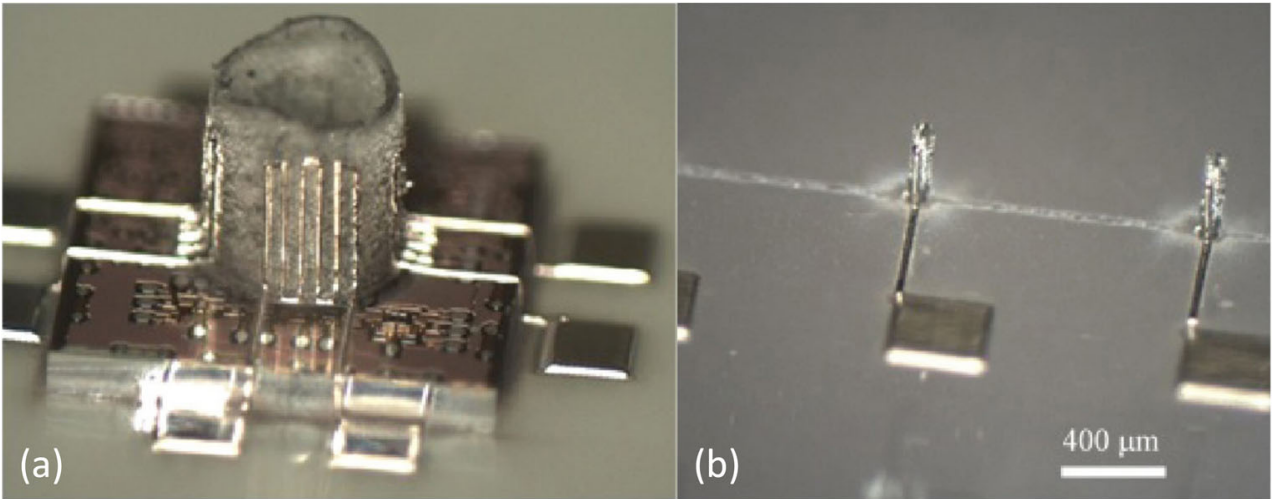

comparable performance. As a result, AJP is again presented as an attractive technique for low-cost fabrication and prototyping, especially when combined with other additive techniques [75].

\subsection{Active electronic components}

Active electronic components either require power to work or can introduce net power into a circuit. Active electronic components tend to be multi-material structures which are more complex when compared to passive electronics. Many implementations of active components use AJP as part of a hybrid process chain to produce the final components. AJP is attractive for the deposition of these devices by allowing their implementation on non-standard substrates, such as paper, fabric and low-temperature polymers.

\subsubsection{Transistors and switches}

The ubiquity of transistors in modern electronics has made them one of the primary research areas in AJP. A key challenge has been the development of high-capacitance dielectric inks for the gate insulators of thin film transistors (TFTs) while maintaining compatibility with solution processing. Cho et al. [76] were the first to demonstrate the potential of ion gels by using AJP to manufacture a series of organic TFTs with switching speeds up to $10 \mathrm{kHz}$ (Fig. 16), which represented a significant increase over solid polymer electrolytes that were limited to sub- $100 \mathrm{~Hz}$ operation.
A subsequent body of work designing and characterising circuits - low-voltage $(<3 \mathrm{~V})$ invertors and ring oscillators Fig. $17[77,78]$ — based on these AJP electrolyte-gated TFTs immerged showing high efficiency and performance. Later optimisation and characterisation showed current ratios of up to $10^{6}$, off-state drain currents as low as $10^{-10} \mathrm{~A}$ and threshold voltages of $-0.3 \mathrm{~V}$ [5]. Other approaches to develop solution processable, high-capacitance dielectrics have focussed on the development of poly(methylsilsesquioxane) as a gate dielectric in indium-gallium-zinc-oxide transistors [79] or polyfluorinated electrolytes for applications that require higher thermal stability [80].

TFTs manufactured using AJP were found to differ in performance when compared to equivalent devices manufactured using conventional solution processes, such as spin coating. $\mathrm{Wu}$ et al. [79] attributed these variances to differences in the electrolyte structure (pin holes), ingress of impurities or residual solvents in the deposit.

The other main body of research in the development of TFTs focusses on the deposition of single-walled carbon nanotubes as a semi-conductor. Transistors with operating frequencies in the region of $5 \mathrm{GHz}$ have been demonstrated through the deposition of high-purity SWCNT inks [81]. The primary hurdle for using semi-conducting SWCNTs is the production and purification of the CNTs and the associated ink formulations [82]. Recently, refinement techniques that can scale have begun to emerge, with Rother et al. [83] showing a stable polymer-sorted semi-conducting SWCNT ink for
Fig. 16 Schematic and optical micrograph of electrolyte-gated thin film transistor (Reprinted with permission from [76])
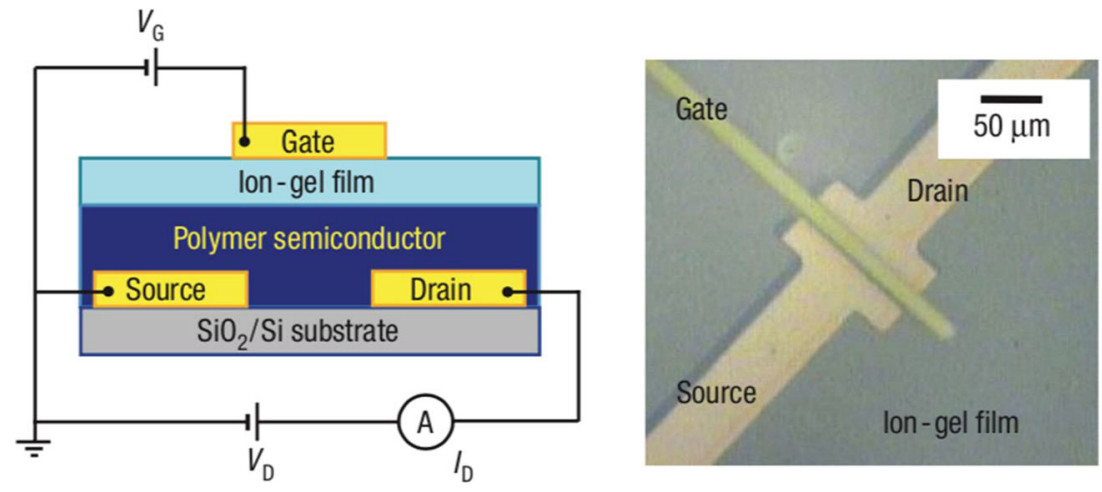
TFTs with high reproducibility. TFTs using semi-conducting SWCNTs have been shown to go through 1000 bending cycles with minimal performance degradation, showing their application to flexible electronics [84]. Other research has focussed on the use of SWCNTs for temperature-stable TFTs [80] and the effect of substrate wetting through oxygen plasma surface treatments [85]. Selective deposition of ethanolamine doping agent on to semiconducting SWCNTs has been shown to change the polarity of TFTs, with P-type transistors being selectively converted to N-type [86]. Through this approach, the researchers could produce a complementary metal oxide semiconductor (CMOS).

$\mathrm{Ha}$ et al. [64] demonstrated the potential of AJP-printed transistors by printing an electrochromic pixel along with a $\mathrm{H}$-bridge drive circuit. The final device featured 23 transistors, 20 resistors, 12 capacitors and 9 dielectric crossovers, all printed in situ using AJP. The interconnecting circuitry was produced using photolithography and electron beam evaporation on to a PET substrate. The final circuit was found to operate at $1 \mathrm{~V}$ with a high degree of stability over 600 test cycles. Although the individual components in this work had been previously demonstrated, this work is the first that demonstrates their application in a more complex circuit.

\subsubsection{Organic light-emitting diodes}

The growth of modern display technology has stirred interest in techniques for the production of high-efficiency displays that do not require conventional vacuum processing techniques. AJP at ambient conditions could lead to a cost reduction while enabling increased performance through design flexibility - even a relatively simple implementation of AJPs, which deposited a PEDOT:PSS grid on the anode of an organic light-emitting diode (OLED), saw efficiency improvements over conventional devices by a factor of 2.3 [88].

Tait et al. [89] took this further by demonstrating the deposition poly(N-vinylcarbazole), PEDOT:PSS and $\mathrm{MoO}_{3}$ as part of functional OLED structures (Fig. 18) while studying the effects of flow rates, stand-off height (up to $15 \mathrm{~mm}$ ), nozzle speed and temperature on the deposition quality. The remaining components of the OLED - the top electron transport layer, cathode and metal oxide layer - were patterned using more conventional shadow mask vacuum evaporation. Their conservative devices produced RGB pixels at a density of $144 \mathrm{ppi}$; however, through optimisation, they suggest that densities as high as 500 ppi may be feasible. Although unlikely to compete with the high-pixel densities of other techniques, it is an attractive approach for large-scale devices that are dimensionally and financially constrained by masked vacuum manufacture.

\subsubsection{Photovoltaics}

As with display technologies, AJP is being used as a tool to transition towards atmospheric processing of photovoltaics (PV). Contactless techniques that allow processing of thinner silicon wafers without damage are increasingly being investigated over more widely adopted screen printing techniques to further reduce manufacturing cost and increase size scales. Initial applications of AJP to PV applications focussed on the metallisation of silicon cells, which was achieved through direct printing of a conductive ink (silver [90], aluminium [91]) or printing of a seed material followed by an electroplating process in a similar way to the techniques discussed in Section 5.1.1. As metallisation aims to minimise the shadowing of the cell while maintaining high conductivity to improve the efficiency, the relatively high-resolution of AJP

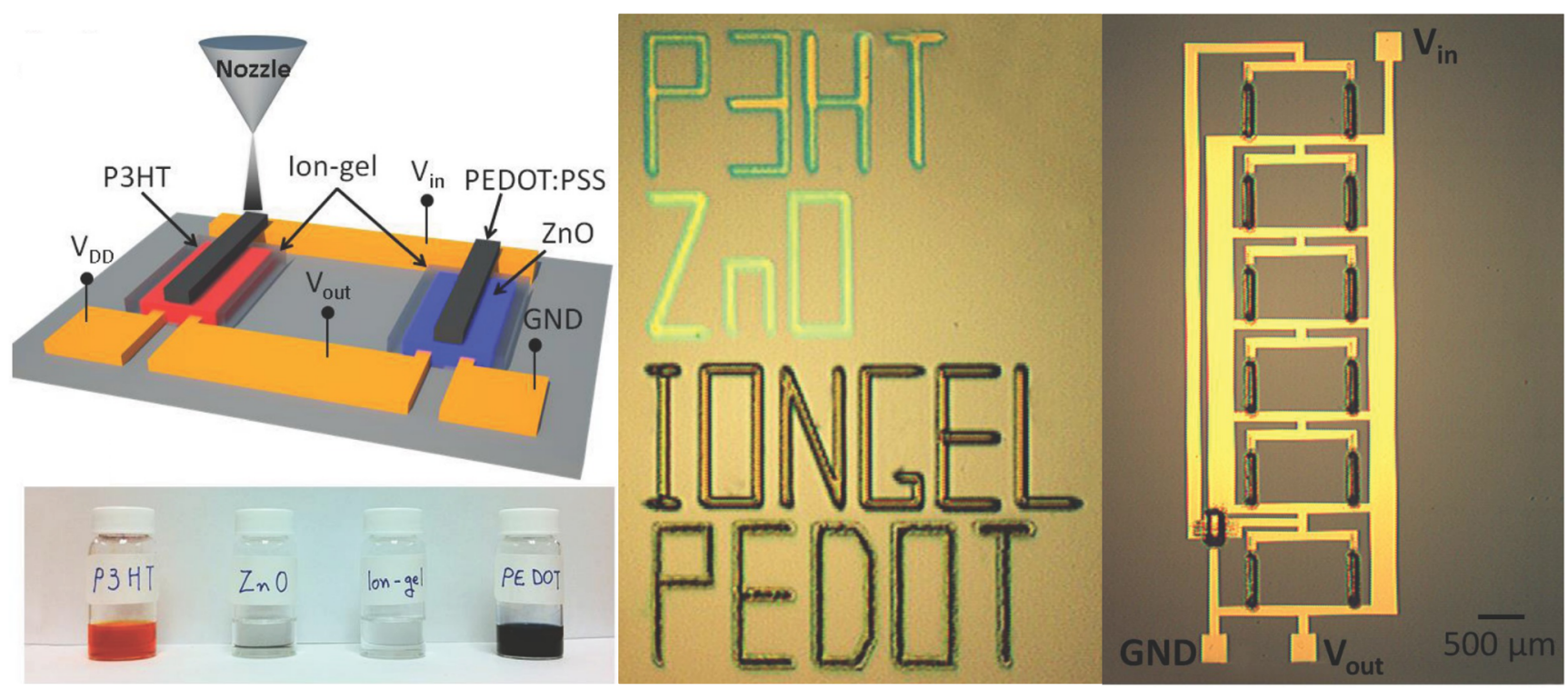

Fig. 17 AJP deposition of P3HT, Zno, PEDOT:PSS, and an Ion-gel for a 5-stage ring oscillator (Reproduced from [77]) 

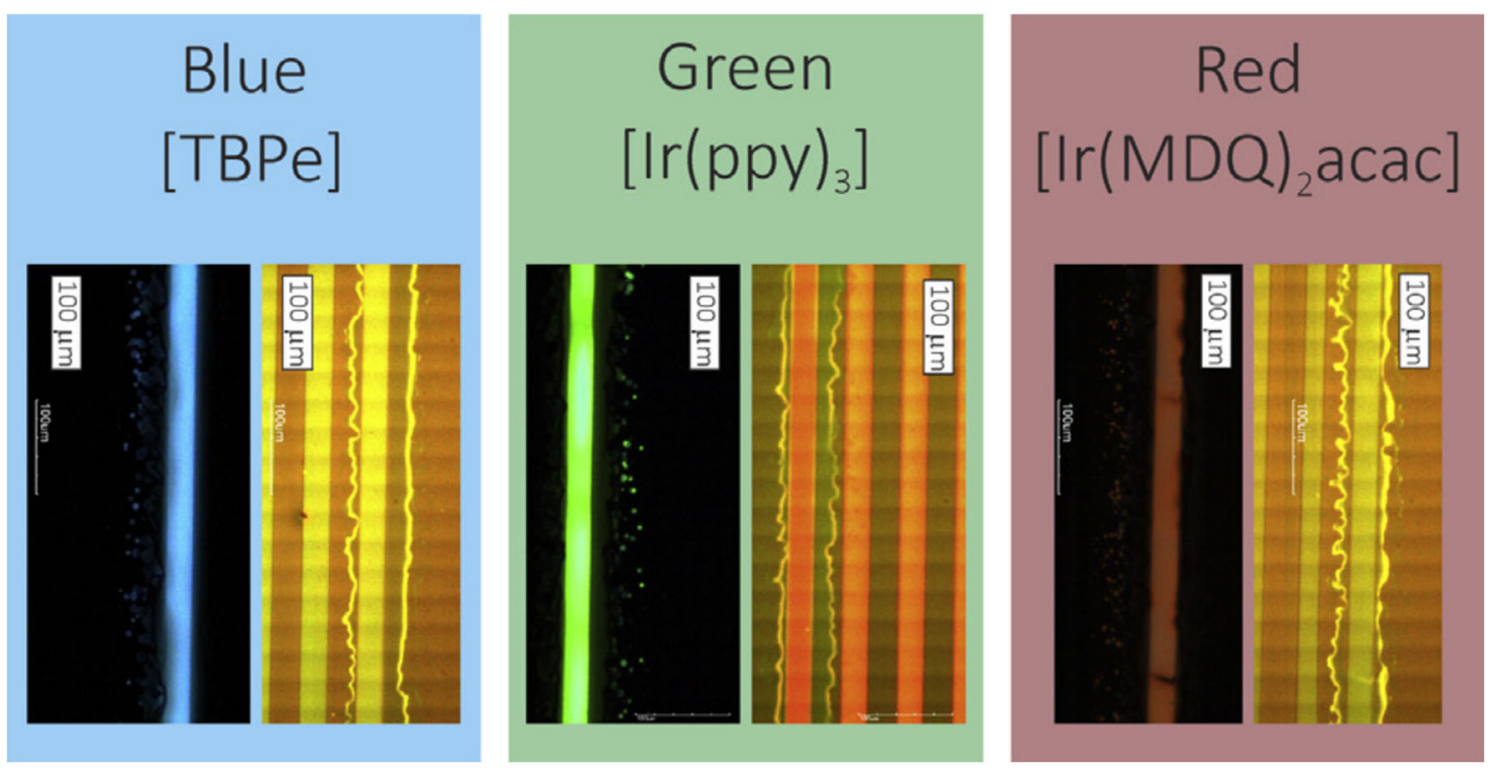

Fig. 18 Printed blue, green and red OLEDs (Reprinted from [89])

when compared to other large area patterning techniques presents an attractive approach.

The manufacture of PVs using direct write processes is dependent on the development of suitable solution processable materials. Earth-abundant materials, particularly perovskite and kesterite materials, are gaining attention for their ease of processing and relatively low cost. Williams et al. [92] investigated the deposition of material precursors that can be annealed to form copper-zinc-tin-sulfide features. Deposits with low solvent content were preferred as it limited cracking during drying. However, as is typical of dry deposits, this led to porous films that required secondary annealing and compaction processes to produce dense, crack-free nanocrystal films. More recently, Bag et al. [93] used AJP to deposit perovskite films as part of a functional solar cell that achieved power conversion efficiencies as high as $15.4 \%$. Their work extended the process to investigate the production of solar cells on non-planar surfaces, demonstrating a hemispherical device with efficiencies of $\sim 5.4 \%$.

A technique for patterning dielectric materials, which are used for insulating and passivation layers in solar cells, used AJP's selective deposition to produce localised chemical etching on a series of silicon substrates coated with silicon dioxide, silicon nitride, silicon oxynitride and aluminium oxide [94]. In this approach, a bulk layer of polyacrylic acid was spin-coated on to the coated silicon substrate before AJP was used to deposit an ammonium fluoride solution. The combination of polyacrylic acid and ammonium fluoride formed localised areas of hydrofluoric acid that etched the underlying dielectric with a minimum feature size approaching $20 \mu \mathrm{m}$. The remaining hydrofluoric acid and polyacrylic acid can, then, be rinsed from the substrate using DI water.

\subsubsection{Fuel cells}

Sukeshini et al. [95-97] published a series of papers investigating the deposition of a yttria-stabilised zirconia (YSZ) electrolyte, a strontium-doped lanthanum manganate (LSM) cathode and a YSZ/LSM composite interlayer for use in solid oxide fuel cells (SOFCs). The interlayer material was facilitated by a dual atomisation configuration that combined two aerosol streams prior to deposition. Despite substandard performance of the developed button cell, an investigation of processing parameters highlighted how the geometry and microstructure can be manipulated to improve device performance. Subsequent optimisation efforts explored this and found that the power densities of the button cell could be varied from 200 to $460 \mathrm{~mW} / \mathrm{cm}^{2}$ simply by controlling the process parameters [96].

Further improvements in performance were found by grading the composition of a YSZ/NiO interlayer through ondemand mixing. This approach allowed the ratio of the composite to be varied on consecutive layers, thereby reducing the ohmic resistance of the device and improving overall performance. Despite this, the button cell still presented substandard performance and further optimisation, in terms of processing, materials and ink formulation, is required before AJP becomes a serious technique for the manufacture of SOFCs. An initial study using a gadolinia-doped ceria (GDC)-lanthanum strontium cobalt ferrite (LSCF) cathode as an alternative to LSM has already led to a 2-fold increase in performance [97].

\subsection{Sensors}

AJP is an effective technique for the manufacture of highresolution sensors that enable researchers to rapidly iterate 
designs through the modification of geometry and materials. New types of sensors are being produced on a greater range of substrates. Embedding sensors within components by direct printing also presents an opportunity for a deeper understanding of how a component behaves in service.

\subsubsection{Strain gauges}

A number of strain gauges have been developed by Fraunhofer IFAM $[98,99]$ and the Georgia Institute for Technology [100]. At their most simple, strain gauges are patterned conductive traces that experience a change in resistance in response to mechanical strain. Traditionally, these devices are manufactured as part of a film before being adhered to the surface for testing. AJP allows the manufacture of the part directly on to the surface of the component, which removes the need for secondary bonding processes while allowing deposition on to complex surfaces. To produce a strain gauge, Maiwald et al. [98] first deposited a polymer isolation layer before using a commercially available silver ink (Advanced Nano Products) to produce the strain gauge geometry (Fig. 19). Their results show a device with a reliable output for a $500 \mathrm{~N}$ load over 1000 cycles at $0.5 \mathrm{~Hz}$. Similar approaches have been adopted by Zhao et al. [100] to embed silver ink strain gauges in carbon-fibre composite devices without significant impact on the mechanical properties. Their work suggests that AJP is a promising approach for embedded sensors; further work is required to remove defects, optimise curing processes and investigate the interface between the sensor and the carbon fibre prepreg. Recently, Rahman et al. [101] demonstrated a ceramic/metal strain sensor for high-temperature applications.

\subsubsection{Capacitive sensors}

Rahman et al. [102] developed interdigitated capacitive touch sensors through the deposition of silver ink on to a planar glass slide (Fig. 20). The interdigitated fingers of the sensor were approximately $50 \mu \mathrm{m}, 1.5-55 \mathrm{~mm}$ long, $0.5 \mu \mathrm{m}$ thick and had a native capacitance of $1-5 \mathrm{pF}$. A degree of repeatability was shown with an $8 \%$ variance in sensor capacitance over three samples. Simulation and experimental observations showed the capacitance to be insensitive to variation in electrode height, meaning the high surface roughness of their AJ deposits has little impact on device performance. The capacitive sensor's output was shown to be largely dependent on the electrode width as a fraction of electrode pitch. Current work has deposited on to planar glass substrates, but more novelty is expected as researchers use AJP for non-planar and flexible substrates. Andrews et al. [103] printed a capacitive sensor from a carbon nanotube ink that, when pressed to a material, exhibits a linear response between capacitance and material thickness. Another interesting application that uses similarly interdigitated AJP structures for electrostatic adhesion has been proposed for use in miniaturised robotics [104].

\subsubsection{Dielectric elastomer devices}

The Factory Automation and Production Systems (FAPS) group is investigating the use of AJP to produce soft dielectric elastomer devices (DEDs) that can be used for sensing, actuation and energy harvesting [105]. These layered structures consist of a soft dielectric sandwiched between two compliant electrodes. Current DED actuation technology is limited by high driving voltages $(>1 \mathrm{kV})$. Reducing the layer thickness of both the dielectric and electrode is a promising approach to producing a low-voltage DEA. AJP's layer-by-layer approach, combined with its ability to produce thin films, makes it a promising approach to produce DEDs in a single processing step $[106,107]$. Although the production of a functional part has yet to be presented, the deposition of two-part silicone (Elastosil P760) has been achieved using a dual atomisation configuration [108]. It is feasible that the current state-of-theart could be used for DED-based sensing.

\subsubsection{Photodetectors}

Photodetectors are a good example of how AJP can be integrated in to a range of fabrication strategies to produce functional devices. The combination of inkjet printing,
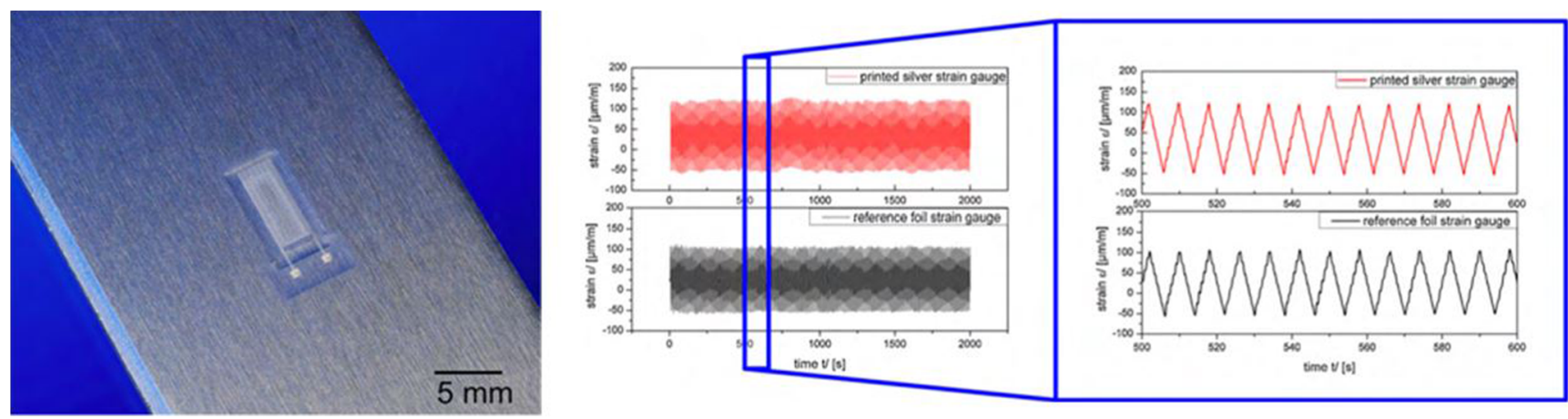

Fig. 19 An AJP gauge and its response compared to a reference foil strain gauge (Reprinted from [98]) 

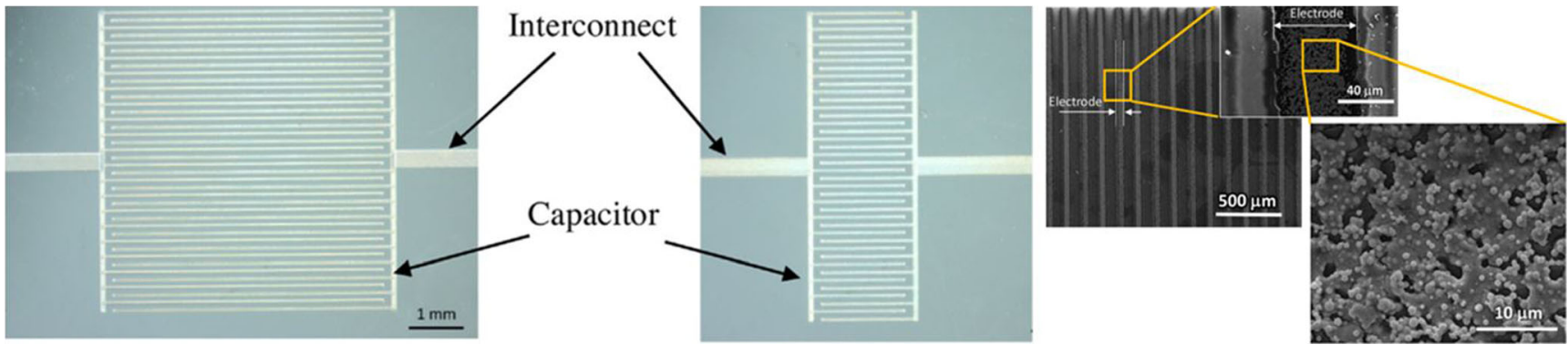

Fig. 20 AJP interdigitated capacitive sensor (Reprinted from [102])

AJP and drop casting leads to the development of a lowcost paper-based photo detector for the visible spectrum [109]. In this work, PEDOT:PSS and P3HT:PCBM layers were deposited by AJP, the silver bottom electrode was deposited using inkjet and a DNA biopolymer was dropcast. An interlayer of PEDOT:PSS was required to increase the adhesion of the silver to P3HT:PCBM, while the DNA biopolymer was required to facilitate a confluent PEDOT:PSS top electrode. A number of different processing and material strategies have been deployed to produce photodetectors [110], including a fully AJP sensor with performance comparable to the state-of-the-art [111]. Ichiyama et al. have used AJP as a technique for the deposition of a fluorescent quantum dot film, with the intention of enabling deep-UV capability in standard CMOS and CCD detector arrays [112].

\subsubsection{Chemical sensors}

Functionalised single-walled carbon nanotube (SWCNT) networks are used in a number of gas-sensing applications. Solution processing of these devices, rather than high-temperature in situ growth, is required to enable manufacture on low-cost polymer and paper substrates. Reduced drying effects, such as the coffee ring effect, in AJP present a simpler pathway to manufacture over inkjet printing or spin coating and have been, recently, demonstrated in the production of a platinum-decorated SWCNT hydrogen sensor [113]. Kuberský et al. [114] demonstrated a $\mathrm{NO}_{2}$ sensor with AJP-printed top CNT electrodes on a series of drop-cast polymer electrolytes. An alternative approach that monitors the current drawn by an AJP electrode array to reduce hydrogen peroxide has also been developed [115]. By introducing glucose oxidase, an enzyme that catalyses the oxidation of glucose to hydrogen peroxide, the sensor was able to detect the concentration of glucose, which could prove useful for biosensing applications. The same group who produced paper-based photo detectors (see Section 5.3.4), refined their technique to produce a sensor capable of vapour-phase chemical detection of water and other volatile organic compounds [116].

\subsection{Three-dimensional structures}

AJP has primarily been used for surface patterning, and researchers are beginning to explore its potential for expanding additive manufacturing with the hope that it can help bridge the gap between size scales. Saleh et al. [9] demonstrated the production of hierarchical structures with features that span 5 orders of magnitude (Fig. 21). Rapid solvent evaporation in a 90-110 ${ }^{\circ} \mathrm{C}$ environment was required to solidify the ink on deposition, while secondary processing was used to remove the binder and sinter the nanoparticle ink. Control of the binder content, nanoparticle size and sintering conditions allowed the authors to manipulate the porosity of the trusses within the lattices. This work was completed using a silver nanoparticle ink; however, it has been stipulated that the approach can be readily transferred to any ink that can form a nanoparticle suspension. Subsequent work has presented these lattices as candidates for electrodes in lithium ion batteries [117] and characterised the mechanical strength of micropillars under compressive load [118].

An alternative approach to produce $3 \mathrm{D}$ structures used AJP to deposit thin layers $(5-35 \mu \mathrm{m})$ of inks on to non-planar surfaces that were subsequently cured through exposure to a UV laser. This hybrid approach combines the thin layer capabilities of AJP with the fine feature capabilities of laser-based direct write to produce high-resolution structures. Although these studies were completed with PDMS [8] and pentaerythritol triacrylate (PETA) [7] (Fig. 22), it is easy to see how this can be expanded to accommodate any UV-curable material. The combination of AJP and laser-based direct write may also present a pathway to multi-material stereolithography that is difficult using conventional VAT-based processes.

\subsection{Applications in biology}

Biological applications of AJP have focussed on techniques for either patterning cellular structures or printing biological molecules, such as proteins, enzymes and strands of DNA. Early work attempted to spatially position mammalian (3T3 mouse fibroblast) cells by direct deposition of the cells and surrounding growth media on the surface of a Petri dish [12]. A viability study showed the deposited cells to have $87 \%$ 
Fig. 21 3D AJP hierarchical silver lattices spanning 5 length scales (Reprinted from [9])
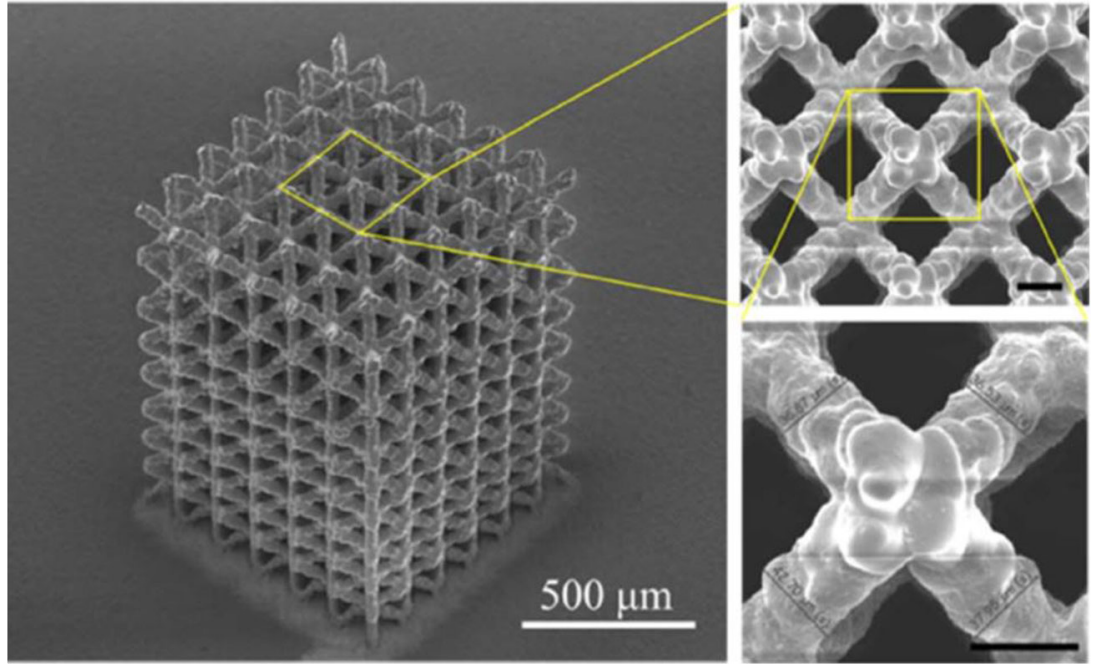

viability compared to $97 \%$ of the control group. Low viability and an inability to control cell migration post-deposition present a significant challenge for this type of approach.

An alternative created regions of preferential adhesion for cells on the surface of a substrate through either positive or negative patterning. In this work, De Silva et al. [119] created regions of preferential adhesion on PDMS-coated Petri dishes by AJP of laminin and poly-ethylenimine. After patterning, the cells were cultured on the surface of the substrate, and higher cell densities were found in the patterned region. Certain cell types were, even, found to elongate and align in the direction of the printed features. The inverse effectnegative patterning - was also shown by patterning glass substrates with PDMS and PTFE. In the negative case, the cells were identified as migrating towards the less hydrophobic glass surface over time, demonstrating their preference for adhesion to intermediate to high-surface tension substrates.

The production of ceramic calcium phosphate substrates for bone cell growth studies has been completed as part of a comparison between AJP, laser ablation and microcontact printing [120]. Geometric and cell proliferation analysis showed AJP to be a useful tool for investigating cell growth on ceramic microstructures with minimal toxicity; however, it does highlight issues relating to system variability and slow processing times when compared to the other techniques.

The deposition of bio-molecules with high spatial resolution is a key to the development of miniaturised test platforms that can be used for fundamental studies, drug/toxicology screening and biological sensing. Grunwald et al. [17] demonstrated the deposition of a series of fluorescent proteins, strands of DNA and active enzymes with minimal impact on their biological activity before going on to compare the technique with other printing processes. The low shear forces present in the AJP process enable the deposition of complex high-molecular weight molecules without denaturing their structure, as shown by the deposition of DNA molecules suspended in a phosphate-buffered saline solution. Although successful in deposition, the authors argue that the slow processing time and lack of parallel deposition in most AJP configurations present a hurdle for the mass production of microarray structures and other test platforms.
Fig. 22 SEM images of (a) $2 \mathrm{~S}$ square grid pattern and (b) $3 \mathrm{D}$ cone array structures (Reprinted from [7])
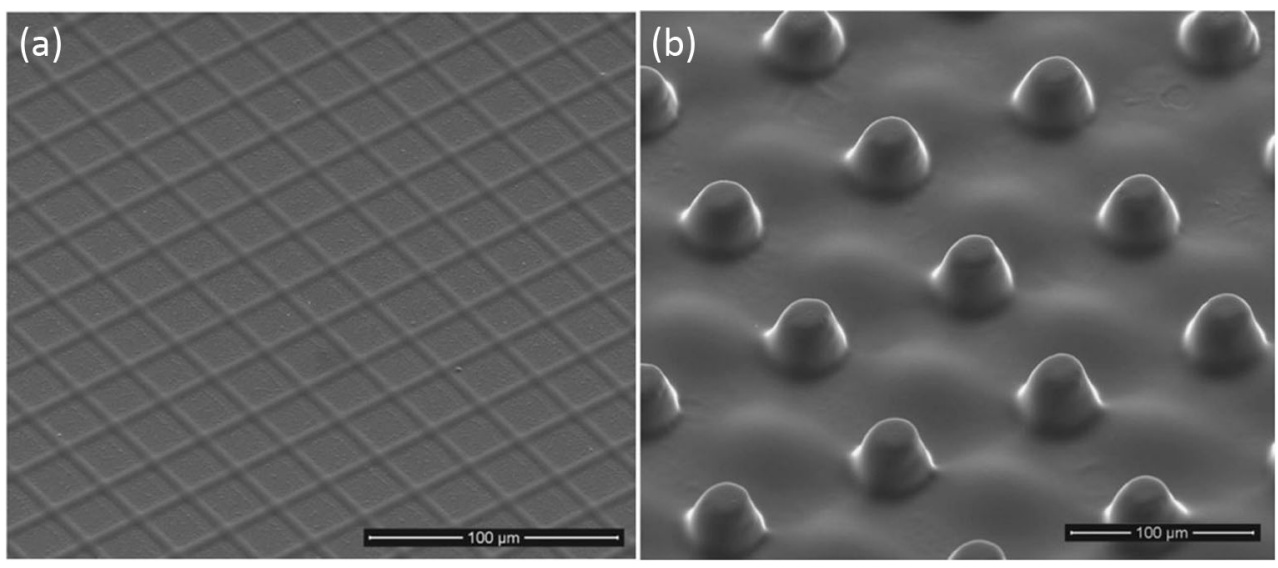


\section{Future direction of aerosol-based direct write}

Printed electronics has been a key driver for the development of the AJP process and is likely to continue as a commercial motivation. Basic circuit elements have been demonstrated in isolation, with examples of complete circuitry only beginning to emerge more recently through hybrid processing. Improving the capability of printed devices will be important in the development of AJP technology, but its lower resolution than lithographic processes means that the greatest short-term impact of AJP will be in applications that harness the flexible nature of the process along with unique characteristics to provide increased function and value. For example, the high conformity offered by AJP increases the design freedom for electronics packaging and conformal antenna [68], while largearea, ambient processing is appealing [19] for economical manufacture of photovoltaics and display technologies.

Beyond the technology's original scope, researchers are using AJP to impact fast-growing topics as diverse as biotechnology and robotics. Novel design and manufacturing has led to innovation in lab-on-a-chip devices [121], and the convergence of these techniques with advanced printing, such as AJP, will provide further opportunities through sensing, selective catalysation, cell seeding and directed cell growth [119].

Additive techniques in soft robotics have been well demonstrated [122], with their ability to selectively and spatially vary stiffness enabling new functionality in soft systems. AJP offers to build on this through the deposition of sensing elements and other electronics within their bodies, paving the way for improved proprioceptive and environmental sensing. Material and process flexibility makes AJP an ideal candidate for implementation alongside other additive techniques for the repeatable, hybrid manufacture of soft robotics - a goal that has recently been highlighted by the research community [123].

Many applications of AJP are facilitated through the formulation of materials with the required processing and functional characteristics. Although AJP has expanded the range of printable viscosities and enabled the deposition of two-part and composites, ink formulation requires a large body of empirical work for consistent deposition. Defining the criteria for a suitable ink through process modelling and experimental observation will accelerate the adoption of the process in commercial settings by decreasing development time scales and cost [24].

Given wider manufacturing research and industrial developments, such as the Internet of Things and Industry 4.0, AJP is well positioned to become an underpinning technology for enabling the creation of more connected and intelligent products. Its extreme versatility gives it the potential to disrupt a host of manufacturing environments; from conventional electronics and sensing to biological and chemical manufacturing applications. As investment increases and applications are recognised, the reliability of the system will increase through improved understanding of material and processing conditions. Its increased adoption will likely be driven by the development of devices with increased performance that reflect the unique capabilities of the process.

Acknowledgments We kindly acknowledge our research funding from the Engineering and Physical Sciences Research Council. This includes a number of our activities which incorporate AJP as a Hybrid Manufacturing Process, namely grants EP/L02067X/2, EP/M026388/1, and EP/P027687/1.

Open Access This article is distributed under the terms of the Creative Commons Attribution 4.0 International License (http:// creativecommons.org/licenses/by/4.0/), which permits unrestricted use, distribution, and reproduction in any medium, provided you give appropriate credit to the original author(s) and the source, provide a link to the Creative Commons license, and indicate if changes were made.

\section{References}

1. Mahajan A, Frisbie CD, Francis LF (2013) Optimization of aerosol jet printing for high-resolution, high-aspect ratio silver lines. ACS Appl Mater Interfaces 5:4856-4864. https://doi.org/10.1021/ am400606y

2. Goth C, Putzo S, Franke J (2011) Aerosol jet printing on rapid prototyping materials for fine pitch electronic applications. In: 2011 IEEE 61st Electronic Components and Technology Conference (ECTC). IEEE, pp 1211-1216

3. Seifert T, Sowade E, Roscher F, Wiemer M, Gessner T, Baumann RR (2015) Additive manufacturing technologies compared: morphology of deposits of silver ink using inkjet and aerosol jet printing. Ind Eng Chem Res 54:769-779. https://doi.org/10.1021/ ie $503636 \mathrm{c}$

4. Meruga JM, Baride A, Cross W, Kellar JJ, May PS (2014) Redgreen-blue printing using luminescence-upconversion inks. J Mater Chem C 2:2221. https://doi.org/10.1039/c3tc32233e

5. Kim SH, Hong K, Lee KH, Frisbie CD (2013) Performance and stability of aerosol-jet-printed electrolyte-gated transistors based on poly(3-hexylthiophene). ACS Appl Mater Interfaces 5:6580 6585. https://doi.org/10.1021/am401200y

6. Secor EB, Hersam MC (2015) Emerging carbon and post-carbon nanomaterial inks for printed electronics. J Phys Chem Lett 6: 620-626. https://doi.org/10.1021/jz502431r

7. Obata K, Klug U, Koch J et al (2014) Hybrid micro-stereolithography by means of aerosol jet printing technology. J Laser Micro Nanoeng 9:242-247. https://doi.org/10.2961/jlmn.2014. 03.0012

8. Obata K, Schonewille A, Slobin S, Hohnholz A, Unger C, Koch J, Suttmann O, Overmeyer L (2017) Hybrid 2D patterning using UV laser direct writing and aerosol jet printing of UV curable polydimethylsiloxane. Appl Phys Lett 111:121903. https://doi.org/10. 1063/1.4996547

9. Saleh MS, Hu C, Panat R (2017) Three-dimensional microarchitected materials and devices using nanoparticle assembly by pointwise spatial printing. Sci Adv 3:e1601986. https://doi. org/10.1126/sciadv. 1601986

10. Paulsen JA, Renn M, Christenson K, Plourde R (2012) Printing conformal electronics on 3D structures with aerosol jet technology. In: FIIW 2012-2012 Future of Instrumentation International Workshop Proceedings. pp 47-50 
11. Maher M, Smith A, Margiotta J (2014) A synopsis of the Defense Advanced Research Projects Agency (DARPA) investment in additive manufacture and what challenges remain. pp 897002 897009

12. Marquez GJ, Renn MJ, Miller WD (2001) Aerosol-based directwrite of biological materials for biomedical applications. MRS Proc 698:Q5.2.1. https://doi.org/10.1557/PROC-698-Q5.2.1

13. Tait JG, Witkowska E, Hirade M, Ke TH, Malinowski PE, Steudel S, Adachi C, Heremans P (2015) Uniform aerosol jet printed polymer lines with 30 ??m width for 140 ppi resolution RGB organic light emitting diodes. Org Electron physics, Mater Appl 22:40-43. https://doi.org/10.1016/j.orgel.2015.03.034

14. Optomec aerosol jet videos. https://www.optomec.com/resources/ 3d-printing-application-videos/. Accessed 19 Mar 2018

15. Gupta AA, Bolduc A, Cloutier SG, Izquierdo R (2016) Aerosol jet printing for printed electronics rapid prototyping. In: 2016 IEEE International Symposium on Circuits and Systems (ISCAS). IEEE, pp 866-869

16. Folgar CE, Suchicital C, Priya S (2011) Solution-based aerosol deposition process for synthesis of multilayer structures. Mater Lett 65:1302-1307. https://doi.org/10.1016/j.matlet.2011.01.069

17. Grunwald I, Groth E, Wirth I, Schumacher J, Maiwald M, Zoellmer V, Busse M (2010) Surface biofunctionalization and production of miniaturized sensor structures using aerosol printing technologies. Biofabrication 2:014106. https://doi.org/10.1088/ 1758-5082/2/1/014106

18. Cai F, Chang Y-H, Wang K, Zhang C, Wang B, Papapolymerou J (2016) Low-loss 3-D multilayer transmission lines and interconnects fabricated by additive manufacturing technologies. IEEE Trans Microw Theory Tech 64:3208-3216. https://doi.org/10. 1109/TMTT.2016.2601907

19. Huang Q, Zhu Y (2019) Printing conductive nanomaterials for flexible and stretchable electronics: a review of materials, processes, and applications. Adv Mater Technol 0:1800546. https://doi. org/10.1002/admt.201800546

20. Optomec (2017) Aerosol jet technology for 3D printed electronics. https://www.optomec.com/printed-electronics/aerosol-jettechnology. Accessed 01 April 2019

21. May KR (1973) The collison nebulizer: description, performance and application. J Aerosol Sci 4:235-243. https://doi.org/10.1016/ 0021-8502(73)90006-2

22. Goth C, Putzo S, Franke J (2011) Aerosol jet printing on rapid prototyping materials for fine pitch electronic applications. In: Proceedings-Electronic Components and Technology Conference. pp 1211-1216

23. Smith M, Choi YS, Boughey C, Kar-Narayan S (2017) Controlling and assessing the quality of aerosol jet printed features for large area and flexible electronics. Flex Print Electron 2. https://doi.org/10.1088/2058-8585/aa5af9

24. Secor EB (2018) Principles of aerosol jet printing. Flex Print Electron. https://doi.org/10.1088/2058-8585/aace28

25. Binder S, Glatthaar M, Rädlein E (2014) Analytical investigation of aerosol jet printing. Aerosol Sci Technol 48:924-929. https:// doi.org/10.1080/02786826.2014.940439

26. Chen G, Gu Y, Tsang H, Hines DR, Das S (2018) The effect of droplet sizes on overspray in aerosol-jet printing. Adv Eng Mater 20:1701084. https://doi.org/10.1002/adem.201701084

27. Salary R, Lombardi JP, Samie Tootooni M, Donovan R Rao PK, Poliks MD (2016) In situ sensor-based monitoring and computational fluid dynamics (CFD) modeling of aerosol jet printing (AJP) process. In: ASME 2016 11th International Manufacturing Science and Engineering Conference

28. Deiner LJ, Reitz TL (2017) Inkjet and aerosol jet printing of electrochemical devices for energy conversion and storage. Adv Eng Mater 19
29. Yang C, Zhou E, Miyanishi S, Hashimoto K, Tajima K (2011) Preparation of active layers in polymer solar cells by aerosol jet printing. ACS Appl Mater Interfaces 3:4053-4058. https://doi. org/10.1021/am200907k

30. Paulsen JA, Renn MJ (2006) Maskless printing of miniature polymer thick film resistors for embedded applications. IPC 3rd Int Conf Embed Technol 2

31. Christenson KK, Paulsen JA, Renn MJ, et al (2011) Direct printing of circuit boards using aerosol jet@. In: 27th International Conference on Digital Printing Technologies, Technical Program and Proceedings. pp 433-436

32. Carter M, Amundson T, Colvin J, Sears J (2007) Characterization of soft magnetic nano-material deposited with M3D technology. J Mater Sci 42:1828-1832. https://doi.org/10.1007/s10853-006-0695-2

33. Mette A, Richter PL, Hörteis M, Glunz SW (2007) Metal aerosol jet printing for solar cell metallization. Prog Photovolt Res Appl 15:621-627. https://doi.org/10.1002/pip.759

34. Drew K, Hopman S, Hörteis M, Glunz SW, Granek F (2011) Combining laser chemical processing and aerosol jet printing: a laboratory scale feasibility study. Prog Photovolt Res Appl 19: 253-259. https://doi.org/10.1002/pip.1014

35. Kalio A, Leibinger M, Filipovic A, Krüger K, Glatthaar M, Wilde J (2012) Development of lead-free silver ink for front contact metallization. Sol Energy Mater Sol Cells 106:51-54. https://doi. org/10.1016/j.solmat.2012.05.044

36. Tamari Y, Gautrein A, Schmiga C, Binder S, Glatthaar M, Glunz SW (2014) Synthesis of a lead- and particle-free metal-organic ink for front side metallization of crystalline silicon solar cells. Energy Procedia 55:708-714. https://doi.org/10.1016/j.egypro.2014.08.049

37. Padovani S, Sinesi S, Priante S, et al (2010) New method for headup display realization by mean of chip on board and aerosol jet process. In: 3rd Electronics System Integration Technology Conference (ESTC). IEEE, pp 1-3

38. Zhan Z, Yu L, Wei J, Zheng C, Sun D, Wang L (2014) Application of aerosol jet technology in through-via interconnection for MEMS wafer-level packaging. Microsyst Technol 21:451-455. https://doi.org/10.1007/s00542-014-2107-x

39. Seifert T, Baum M, Roscher F, Wiemer M, Gessner T (2015) Aerosol jet printing of nano particle based electrical chip interconnects. Mater Today Proc 2:4262-4271. https://doi.org/10.1016/j. matpr.2015.09.012

40. Syed-Khaja A, Hoerber J, Gruber C, Franke J (2016) A novel approach for thin-film Ag-sintering process through aerosol jet printing in power electronics. In: 20th European Microelectronics and Packaging Conference and Exhibition: Enabling Technologies for a Better Life and Future, EMPC 2015

41. Stoukatch $S$, Laurent $P$, Dricot $S$, et al (2012) Evaluation of aerosol jet printing (AJP) technology for electronic packaging and interconnect technique. 2012 4th Electron Syst Technol Conf ESTC 2012. https://doi.org/10.1109/ESTC.2012.6542067

42. Kaestle C, Hoerber J, Oechsner F, Franke J (2015) Prospects of wire bonding as an approach for contacting additive manufactured aerosol jet printed structures. In: 2015 European Microelectronics Packaging Conference (EMPC). pp 1-6

43. Khorramdel B, Torkkeli A, Mantysalo M (2017) Electrical contacts in SOI MEMS using aerosol jet printing. IEEE J Electron Devices Soc 6. https://doi.org/10.1109/JEDS.2017.2764498

44. Verheecke W, Van Dyck M, Vogeler F, et al (2012) Optimizing aerosol jet ${ }^{\circledR}$ printing of silver interconnects on polyimide film for embedded electronics applications. In: 8th Int DAAAM Balt Conf "INDUSTRIAL Eng". pp 373-379

45. Kopola P, Zimmermann B, Filipovic A, Schleiermacher HF, Greulich J, Rousu S, Hast J, Myllylä R, Würfel U (2012) Aerosol jet printed grid for ITO-free inverted organic solar cells. Sol Energy Mater Sol Cells 107:252-258. https://doi.org/10.1016/ j.solmat.2012.06.042 
46. Mashayekhi M, Winchester L, Evans L, Pease T, Laurila MM, Mantysalo M, Ogier S, Teres L, Carrabina J (2016) Evaluation of aerosol, superfine inkjet, and photolithography printing techniques for metallization of application specific printed electronic circuits. IEEE Trans Electron Devices 63:1246-1253

47. Vunnam S, Ankireddy K, Kellar J, Cross W (2013) Surface modification of indium tin oxide for direct writing of silver nanoparticulate ink micropatterns. Thin Solid Films 531:294 301. https://doi.org/10.1016/j.tsf.2013.01.047

48. Mahajan A, Francis LF, Frisbie CD (2014) Facile method for fabricating flexible substrates with embedded, printed silver lines. ACS Appl Mater Interfaces 6:1306-1312. https://doi.org/10.1021/ am405314s

49. Chang Y-HY, Wang K, Wu C, Chen Y, Zhang C, Wang B (2015) A facile method for integrating direct-write devices into threedimensional printed parts. Smart Mater Struct 24:065008. https:// doi.org/10.1088/0964-1726/24/6/065008

50. Shankar R, Groven L, Amert A, Whites KW, Kellar JJ (2011) Non-aqueous synthesis of silver nanoparticles using tin acetate as a reducing agent for the conductive ink formulation in printed electronics. J Mater Chem 21:10871. https://doi.org/10.1039/ c0jm04521g

51. Werner C, Godlinski D, Zöllmer V, Busse M (2013) Morphological influences on the electrical sintering process of aerosol jet and ink jet printed silver microstructures. J Mater Sci Mater Electron 24:4367-4377. https://doi.org/10.1007/s10854013-1412-y

52. Rahman MT, McCloy J, Ramana CV, Panat R (2016) Structure, electrical characteristics, and high-temperature stability of aerosol jet printed silver nanoparticle films. J Appl Phys 120:075305. https://doi.org/10.1063/1.4960779

53. Hoerber J, Goth C, Franke J, Hedges M (2011) Electrical functionalization of thermoplastic materials by aerosol jet printing. In: 2011 IEEE 13th Electronics Packaging Technology Conference. IEEE, pp 813-818

54. Schuetz K, Hoerber J, Franke J (2014) Selective light sintering of aerosol-jet printed silver nanoparticle inks on polymer substrates. In: AIP Conference Proceedings. pp 732-735

55. Kamyshny A, Magdassi S (2014) Conductive nanomaterials for printed electronics. Small 10:3515-3535

56. Reboun J, Pretl S, Navratil J, Hlina J (2016) Bending endurance of printed conductive patterns on flexible substrates. In: 2016 39th International Spring Seminar on Electronics Technology (ISSE). IEEE, pp 184-188

57. Jabari E, Toyserkani E (2015) Micro-scale aerosol-jet printing of graphene interconnects. Carbon N Y 91:321-329. https://doi.org/ 10.1016/j.carbon.2015.04.094

58. Jabari E, Toyserkani E (2016) Aerosol-jet printing of highly flexible and conductive graphene/silver patterns. Mater Lett 174:40 43. https://doi.org/10.1016/j.matlet.2016.03.082

59. Kan W, Chang Y-H, Zhang C, Wang B (2016) Conductive-ondemand: tailorable polyimide/carbon nanotube nanocomposite thin film by dual-material aerosol jet printing. Carbon N Y 98: 397-403. https://doi.org/10.1016/j.carbon.2015.11.032

60. Reitberger T, Franke J, Hoffmann G-A, et al (2016) Integration of polymer optical waveguides by using flexographic and aerosol jet printing. In: 2016 12th International Congress Molded Interconnect Devices (MID). IEEE, pp 1-6

61. Reitberger T, Hoerber J, Schramm R et al (2015) Aerosol jet printing of optical waveguides. In: 2015 38th International Spring Seminar on Electronics Technology (ISSE). IEEE, pp 5-10

62. Hoffmann G, Reitberger T, Franke J, Overmeyer L (2016) Conditioning of surface energy and spray application of optical waveguides for integrated intelligent systems. Procedia Technol 26:169-176. https://doi.org/10.1016/j.protcy.2016.08.023
63. Reitberger T, Hoffmann G-A, Wolfer T, et al (2016) Printing polymer optical waveguides on conditioned transparent flexible foils by using the aerosol jet technology. In: List-Kratochvil EJW (ed) Proceedings volume 9945, printed memory and circuits II. p 99450G

64. Ha M, Zhang W, Braga D, Renn MJ, Kim CH, Frisbie CD (2013) Aerosol-jet-printed, 1 volt H-bridge drive circuit on plastic with integrated electrochromic pixel. ACS Appl Mater Interfaces 5: 13198-13206. https://doi.org/10.1021/am404204q

65. Gu Y, Park D, Bowen D, et al (2018) Direct-write printed, solidcore solenoid inductors with commercially relevant inductances. Adv Mater Technol

66. Xu BL, Zhao Y, Yu LK, Xu B, Zhang HE, Lv WL, Sun DH (2013) Aerosol jet printing on radio frequency IDentification tag applications. Key Eng Mater 562-565:1417-1421. https://doi.org/10. 4028/www.scientific.net/KEM.562-565.1417

67. Rahman MT, Panat R, Heo D (2015) 3-D antenna structures using novel direct-write additive manufacturing method. In: ASME 2015 International Technical Conference and Exhibition on Packaging and Integration of Electronic and Photonic Microsystems, InterPACK 2015, collocated with the ASME 2015 13th International Conference on Nanochannels, Microchannels, and Minichannels. American Society of Mechanical Engineers, School of Mechanical and Materials Engineering, Washington State University, Pullman, WA, United States

68. Rahman MT, Panat R, Heo D (2015) 3-D antenna structures using novel direct-write additive manufacturing method. In: Volume 3: Advanced fabrication and manufacturing; emerging technology frontiers; energy, health and water-applications of nano-, microand mini-scale devices; MEMS and NEMS; technology update talks; thermal management using micro channels, jets, sprays. ASME, $p$ V003T03A002

69. Rahman T, Renaud L, Heo D, Renn M, Panat R (2015) Aerosol based direct-write micro-additive fabrication method for sub-mm 3D metal-dielectric structures. J Micromech Microeng 25:107002. https://doi.org/10.1088/0960-1317/25/10/107002

70. Fan Cai, Pavlidis S, Papapolymerou J, et al (2014) Aerosol jet printing for 3-D multilayer passive microwave circuitry. In: 2014 44th European Microwave Conference. IEEE, pp 512-515

71. He Y, Becker M, Grotjohn T, et al (2017) RF characterization of coplanar waveguide (CPW) transmission lines on singlecrystalline diamond platform for integrated high power RF electronic systems. IEEE MTT-S Int Microw Symp Dig 517-520. https://doi.org/10.1109/MWSYM.2017.8058613

72. Cai F, Chang Y, Wang K, et al (2014) High resolution aerosol jet printing of D-band printed transmission lines on flexible LCP substrate. In: 2014 IEEE MTT-S International Microwave Symposium (IMS2014). IEEE, pp 1-3

73. Lan X, Lu X, Blumenthal T, et al (2015) Ultra-wideband microwave components fabricated using low-cost aerosol-jet printing technology. In: 2015 IEEE Radio and Wireless Symposium (RWS). IEEE, pp 156-158

74. Oakley C, Kaur A, Byford JA, Chahal P (2017) Aerosol-jet printed quasi-optical terahertz filters. In: 2017 IEEE 67th Electronic Components and Technology Conference (ECTC), Orlando, FL, 2017, IEEE, pp 248-253. https://doi.org/10.1109/ ECTC.2017.233

75. Hester J, Nguyen E, Tice J, Radisic V (2017) A novel 3d-printingenabled "roller coaster" transmission line. In: 2017 IEEE Antennas Propag Soc Int Symp Proc 2017-Janua:2639-2640. https://doi.org/10.1109/APUSNCURSINRSM.2017.8073362

76. Cho JH, Lee J, Xia Y, Kim BS, He Y, Renn MJ, Lodge TP, Daniel Frisbie C (2008) Printable ion-gel gate dielectrics for low-voltage polymer thin-film transistors on plastic. Nat Mater 7:900-906. https://doi.org/10.1038/nmat2291

77. Hong K, Kim YH, Kim SH, Xie W, Xu WD, Kim CH, Frisbie CD (2014) Aerosol jet printed, sub-2 V complementary circuits 
constructed from P- and N-type electrolyte gated transistors. Adv Mater 26:7032-7037. https://doi.org/10.1002/adma.201401330

78. Hong K, Kim SH, Lee KH, Frisbie CD (2013) Printed, sub-2V $\mathrm{ZnO}$ electrolyte gated transistors and inverters on plastic. Adv Mater 25:3413-3418. https://doi.org/10.1002/adma.201300211

79. Wu X, Chen Z, Zhou T, Shao S, Xie M, Song M, Cui Z (2015) Printable poly(methylsilsesquioxane) dielectric ink and its application in solution processed metal oxide thin-film transistors. RSC Adv 5:20924-20930. https://doi.org/10.1039/C4RA17234E

80. Li H, Tang Y, Guo W, Liu H, Zhou L, Smolinski N (2016) Polyfluorinated electrolyte for fully printed carbon nanotube electronics. Adv Funct Mater 26:6914-6920. https://doi.org/10.1002/ adfm. 201601605

81. Jones CS, Lu X, Renn M, Stroder M, Shih WS (2010) Aerosol-jetprinted, high-speed, flexible thin-film transistor made using single-walled carbon nanotube solution. Microelectron Eng 87: 434-437. https://doi.org/10.1016/j.mee.2009.05.034

82. Qian L, Xu W, Fan X, Wang C, Zhang J, Zhao J, Cui Z (2013) Electrical and photoresponse properties of printed thin-film transistors based on poly(9,9-dioctylfluorene-co-bithiophene) sorted large-diameter semiconducting carbon nanotubes. J Phys Chem C 117:18243-18250. https://doi.org/10.1021/jp4055022

83. Rother M, Brohmann M, Yang S, Grimm SB, Schieß1 SP, Graf A, Zaumseil J (2017) Aerosol-jet printing of polymer-sorted (6,5) carbon nanotubes for field-effect transistors with high reproducibility. Adv Electron Mater 3:1700080. https://doi.org/10.1002/ aelm.201700080

84. Cao C, Andrews JB, Franklin AD (2017) Completely printed, flexible, stable, and hysteresis-free carbon nanotube thin-film transistors via aerosol jet printing. Adv Electron Mater 3:1700057. https://doi.org/10.1002/aelm.201700057

85. Liu Z, Zhao J, Xu W, Qian L, Nie S, Cui Z (2014) Effect of surface wettability properties on the electrical properties of printed carbon nanotube thin-film transistors on $\mathrm{SiO}_{2} / \mathrm{Si}$ substrates. ACS Appl Mater Interfaces 6:9997-10004. https://doi.org/10.1021/ am502168x

86. Xu Q, Zhao J, Pecunia V, Xu W, Zhou C, Dou J, Gu W, Lin J, Mo L, Zhao Y, Cui Z (2017) Selective conversion from p-type to ntype of printed bottom-gate carbon nanotube thin-film transistors and application in complementary metal-oxide-semiconductor inverters. ACS Appl Mater Interfaces 9:12750-12758. https:// doi.org/10.1021/acsami.7b01666

87. Liu R, Shen F, Ding H, Lin J, Gu W, Cui Z, Zhang T (2013) Allcarbon-based field effect transistors fabricated by aerosol jet printing on flexible substrates. J Micromech Microeng 23:065027. https://doi.org/10.1088/0960-1317/23/6/065027

88. Zhou L, Zhuang JY, Song MS, Su WM, Cui Z (2014) Enhanced performance for organic light-emitting diodes by embedding an aerosol jet printed conductive grid. J Phys D Appl Phys 47: 115504. https://doi.org/10.1088/0022-3727/47/11/115504

89. Tait JG, Witkowska E, Hirade M, Ke TH, Malinowski PE, Steudel S, Adachi C, Heremans P (2015) Uniform aerosol jet printed polymer lines with $30 \mu \mathrm{m}$ width for 140 ppi resolution RGB organic light emitting diodes. Org Electron 22:40-43. https://doi.org/10. 1016/j.orgel.2015.03.034

90. van Hest MFAM, Habas SE, Underwood JM, et al (2010) Direct write metallization for photovoltaic cells and scaling thereof. In: 2010 35th IEEE Photovoltaic Specialists Conference. IEEE, pp 003626-003628

91. Platt HAS, Li Y, Novak JP, van Hest MFAM (2012) Non-contact printed aluminum metallization of Si photovoltaic devices. In: 2012 38th IEEE Photovoltaic Specialists Conference. IEEE, pp 002244-002246

92. Williams BA, Mahajan A, Smeaton MA, Holgate CS, Aydil ES, Francis LF (2015) Formation of copper zinc tin sulfide thin films from colloidal nanocrystal dispersions via aerosol-jet printing and compaction. ACS Appl Mater Interfaces 7:11526-11535. https:// doi.org/10.1021/acsami.5b02484

93. Bag S, Deneault JR, Durstock MF (2017) Aerosol-jet-assisted thin-film growth of $\mathrm{CH} 3 \mathrm{NH} 3 \mathrm{PbI} 3$ perovskites - a means to achieve high quality, defect-free films for efficient solar cells. Adv Energy Mater 1701151:1701151. https://doi.org/10.1002/aenm. 201701151

94. Rodriguez J, Lennon AJ, Luo M, Li Z, Yao Y, Lu PH, Chan C, Wenham SR (2012) Dielectric patterning using aerosol jet printing. J Imaging Sci Technol 56:1-7. https://doi.org/10.2352/J. ImagingSci.Technol.2012.56.4.040502

95. Sukeshini AM, Jenkins T, Gardner P, et al (2010) Investigation of aerosol jet deposition parameters for printing SOFC layers. In: ASME 2010 8th International Fuel Cell Science, Engineering and Technology Conference: Volume 1. ASME, pp 325-332

96. Sukeshini AM, Gardner P, Meisenkothen F, et al (2011) Aerosol jet printing and microstructure of SOFC electrolyte and cathode layers. pp 2151-2160

97. Sukeshini AM, Meisenkothen F, Gardner P, Reitz TL (2013) Aerosol jet?? Printing of functionally graded SOFC anode interlayer and microstructural investigation by low voltage scanning electron microscopy. J Power Sources 224:295-303. https://doi. org/10.1016/j.jpowsour.2012.09.094

98. Maiwald M, Werner C, Zoellmer V, Busse M (2010) INKtelligent printed strain gauges. Sensors Actuators A Phys 162:198-201. https://doi.org/10.1016/j.sna.2010.02.019

99. Maiwald M, Werner C, Zöllmer V, Busse M (2010) INKtelligent printing ${ }^{\circledR}$ for sensorial applications. Sens Rev 30:19-23. https:// doi.org/10.1108/02602281011010763

100. Zhao D, Liu T, Zhang M, Liang R, Wang B (2012) Fabrication and characterization of aerosol-jet printed strain sensors for multifunctional composite structures. Smart Mater Struct 21:115008. https:// doi.org/10.1088/0964-1726/21/11/115008

101. Rahman MT, Moser R, Zbib HM, Ramana CV, Panat R (2018) 3D printed high performance strain sensors for high temperature applications. J Appl Phys 123:024501. https://doi.org/10.1063/1. 4999076

102. Rahman MT, Rahimi A, Gupta S, Panat R (2016) Microscale additive manufacturing and modeling of interdigitated capacitive touch sensors. Sensors Actuators A Phys 248:94-103. https://doi. org/10.1016/j.sna.2016.07.014

103. Andrews JB, Cao C, Brooke MA, Franklin AD (2017) Noninvasive material thickness detection by aerosol jet printed sensors enhanced through metallic carbon nanotube ink. IEEE Sensors J 17:4612-4618. https://doi.org/10.1109/JSEN.2017. 2710085

104. Fessl J, Mach F, Navratil J (2017) Numerical and experimental analysis of electrostatic adhesion force generated by interdigital electrodes. In: 2017 18th Int Symp Electromagn Fields Mechatronics, Electr Electron Eng ISEF 2017 c:1-2. https://doi. org/10.1109/ISEF.2017.8090706

105. Reitelshöfer S, Göttler M, Schmidt P, Treffer P, Landgraf M, Franke J (2016) Aerosol-jet-printing silicone layers and electrodes for stacked dielectric elastomer actuators in one processing device. In: Proc. SPIE 9798, Electroactive Polymer Actuators and Devices (EAPAD)

106. Landgraf M, Reitelshofer S, Franke J, Hedges M (2013) Aerosol jet printing and lightweight power electronics for dielectric elastomer actuators. In: 2013 3rd International Electric Drives Production Conference (EDPC). IEEE, pp 1-7

107. Yoo IS, Landgraf M, Ramer C, Reitelshöfer S, Ziegler C, Franke J (2014) My new colleague has artificial muscles: a DEA based approach for inherently compliant robotic systems. Prod Eng 8: 711-717. https://doi.org/10.1007/s11740-014-0564-9

108. Reitelshofer S, Landgraf M, Graf D, et al (2015) A new production process for soft actuators and sensors based on dielectric 
elastomers intended for safe human robot interaction. In: 2015 IEEE/SICE International Symposium on System Integration (SII). IEEE, pp 51-56

109. Aga RS, Lombardi JP, Bartsch CM, Heckman EM (2014) Performance of a printed photodetector on a paper substrate. IEEE Photon Technol Lett 26:305-308. https://doi.org/10.1109/ LPT.2013.2292830

110. Wang F-X, Lin J, Gu W-B, Liu YQ, Wu HD, Pan GB (2013) Aerosol-jet printing of nanowire networks of zinc octaethylporphyrin and its application in flexible photodetectors. Chem Commun 49:2433-2435. https://doi.org/10.1039/ c3cc38996k

111. Eckstein R, Rödlmeier T, Glaser T, Valouch S, Mauer R, Lemmer U, Hernandez-Sosa G (2015) Aerosol-jet printed flexible organic photodiodes: semi-transparent, color neutral, and highly efficient. Adv Electron Mater 1:1500101. https://doi.org/10.1002/aelm. 201500101

112. Ichiyama R, Ninkov Z, Williams S, et al (2017) Using quantumdots to enable deep-UV sensitivity with standard silicon-based imaging detectors. In: Soskind YG, Olson C (eds) Proceedings of SPIE. p 1011011

113. Liu R, Ding H, Lin J, Shen F, Cui Z, Zhang T (2012) Fabrication of platinum-decorated single-walled carbon nanotube based hydrogen sensors by aerosol jet printing. Nanotechnology 23: 505301. https://doi.org/10.1088/0957-4484/23/50/505301

114. Kuberský P, Altšmíd J, Hamáček A, Nešpůrek S, Zmeškal O (2015) An electrochemical $\mathrm{NO}_{2}$ sensor based on ionic liquid: influence of the morphology of the polymer electrolyte on sensor sensitivity. Sensors 15:28421-28434. https://doi.org/10.3390/ s151128421

115. Yang H, Rahman MT, Du D et al (2016) 3-D printed adjustable microelectrode arrays for electrochemical sensing and biosensing. Sensors Actuators B Chem 230:600-606. https://doi.org/10.1016/ j.snb.2016.02.113
116. Lombardi J, Poliks MD, Zhao W, et al (2017) Nanoparticle based printed sensors on paper for detecting chemical species. In: 2017 IEEE 67th Electronic Components and Technology Conference (ECTC). IEEE, pp 764-771

117. Saleh MS, Li J, Park J, Panat R (2018) 3D printed hierarchicallyporous microlattice electrode materials for exceptionally high specific capacity and areal capacity lithium ion batteries. Addit Manuf 23:70-78. https://doi.org/10.1016/j.addma.2018.07.006

118. Sadeq Saleh M, HamidVishkasougheh M, Zbib H, Panat R (2018) Polycrystalline micropillars by a novel 3-D printing method and their behavior under compressive loads. Scr Mater 149:144-149. https://doi.org/10.1016/j.scriptamat.2018.02.027

119. De Silva MN, Paulsen J, Renn MJ, Odde DJ (2006) Two-step cell patterning on planar and complex curved surfaces by precision spraying of polymers. Biotechnol Bioeng 93:919-927. https:// doi.org/10.1002/bit.20787

120. Große Holthaus M, Rezwan K (2008) Comparison of three microstructure fabrication methods for bone cell growth studies. In: ASME 2008 International Manufacturing Science and Engineering Conference, Volume 2. ASME, pp 483-490

121. Kitsara M, Kontziampasis D, Agbulut O, Chen Y (2019) Heart on a chip: micro-nanofabrication and microfluidics steering the future of cardiac tissue engineering. Microelectron Eng 203-204:44-62. https://doi.org/10.1016/j.mee.2018.11.001

122. Wehner M, Truby RL, Fitzgerald DJ, Mosadegh B, Whitesides GM, Lewis JA, Wood RJ (2016) An integrated design and fabrication strategy for entirely soft, autonomous robots. Nature 536: 451-455. https://doi.org/10.1038/nature19100

123. Wallin TJ, Pikul J, Shepherd RF (2018) 3D printing of soft robotic systems. Nat Rev Mater 3:84-100

Publisher's note Springer Nature remains neutral with regard to jurisdictional claims in published maps and institutional affiliations. 